Dear Author,

Please, note that changes made to the HTML content will be added to the article before publication, but are not reflected in this PDF.

Note also that this file should not be used for submitting corrections. 


\title{
Q1 Fatigue evaluation of a composite railway bridge based on fracture mechanics through global-local dynamic analysis
}

\author{
Q2 Hui Zhou ${ }^{\mathrm{a}}$, Gang Shi ${ }^{\mathrm{b}, *}$, Yuanqing Wang ${ }^{\mathrm{b}}$, Huating Chen ${ }^{\mathrm{a}}$, Guido De Roeck ${ }^{\mathrm{c}}$ \\ ${ }^{a}$ Key Laboratory of Urban Security and Disaster Engineering of Ministry of Education, Beijing University of Technology, Beijing 100124, China \\ ${ }^{\mathrm{b}}$ Key Laboratory of Civil Engineering Safety and Durability of China Education Ministry, Department of Civil Engineering, Tsinghua University, Beijing 100084, China \\ c Department of Civil Engineering, KU Leuven, Kasteelpark Arenberg 40, B-3001 Leuven, Belgium
}

\section{A R T I C L E I N F O}

Article history:

Received 17 October 2014

Received in revised form 21 September 2015

Accepted 4 January 2016

Available online $\mathrm{xxxx}$

\section{Keywords:}

Fatigue evaluation

Composite railway bridge

Linear elastic fracture mechanics (LEFM)

Global-local model

Crack propagation analysis

\begin{abstract}
A B S T R A C T
An enhanced fatigue assessment of critical welded details in a steel-concrete composite railway bridge was car- 15 ried out by fatigue crack propagation analysis based on linear elastic fracture mechanics (LEFM). The most fatigue 16 critical connections concerned in this study were identified by the preliminary fatigue assessment based on the $S-17$ $N$ method in the previous research of the authors Zhou et al. (2013). Three-dimensional crack models of the crit- 18 ical connections were incorporated into the global-local finite element model of the bridge. The stress intensity 19 factor (SIF) histories of the cracks were calculated through dynamic analysis of the bridge due to high-speed train 20 passages, which validated the applicability and the accuracy of the empirical SIF formulas for the concerned 21 bridge details. The fatigue crack growth curve, represented by crack size versus number of train passages, was ob- 22 tained through crack propagation analysis based on the Paris law and LEFM, and fatigue propagation life was pre- 23 dicted for each critical connection. The proposed crack propagation analysis method provides a general and 24 alternative approach to evaluate the fatigue life of welded details in steel bridges.
\end{abstract}

@ 2015 Published by Elsevier Ltd. 26
38

35

\section{Introduction}

In the current design codes for steel structures, such as Eurocode 3 [2], BS 5400 [3] and AASHTO [4] etc., the prevalent fatigue design and assessment method is based on the detail category specified $S$ - $N$ curve and the Palmgren-Miner [5-6] cumulative damage rule. If the necessary test data in the form of fatigue strength curves are available for the specific detail categories, it is simple and efficient to use the nominal stress based $S-N$ method to conduct fatigue design and assessment of a steel bridge. However, in reality, $S-N$ curves are only available for a limited number of structural details, which are given by the classification tables in the design codes [2-4]. Complex structural details that are excluded from the code specified fatigue categories, or multi-axial stress conditions that cause difficulties in determination of the nominal stresses, invalidate the applicability of the nominal stress based $S-N$ method. Furthermore, weld defects, such as welding cracks, incomplete penetrations, inclusions, undercuts, etc., are unavoidable in welded details of steel bridges. The traditional $S-N$ method is inapplicable to evaluate the effect of a specific defect on the fatigue life, while linear elastic fracture mechanics (LEFM) [7-8] can be used to deal with fatigue crack propagation analysis of cracked welded details.

* Corresponding author.

E-mail addresses: zhouhui@bjut.edu.cn (H. Zhou), shigang@mail.tsinghua.edu.cn (G. Shi), wang-yq@mail.tsinghua.edu.cn (Y. Wang), chenhuating@bjut.edu.cn (H. Chen), Guido.DeRoeck@bwk.kuleuven.be (G. De Roeck).
When a fatigue crack is detected in a steel bridge in service, the re- 57 maining fatigue life of the cracked detail needs to be estimated. The 58 LEFM based approaches are able to provide knowledge about crack size 59 and crack growth rate under actual service loads. With this information, 60 it can be decided that either the crack propagates slowly so that enough 61 time is available before retrofitting or the crack propagation is accelerated 62 and the time for repair, retrofitting or replacement is short. Furthermore, 63 the crack propagation information predicted by the LEFM approaches also 64 helps to set up a plan for regular inspection and suitable repair measures 65 before the crack grows to a critical size. The application of the LEFM in fa- 66 tigue crack propagation analysis becomes more and more widely accept- 67 ed [9-14]. Most of the researches on the LEFM based fatigue crack 68 propagation analyses were concentrated on the local structural details 69 and the solutions for the stress intensity factor (SIF) around the crack 70 front [9-10], while only a few efforts [13-14] were made to determine 71 the surrounding stress or deformation histories of the local details 72 which drive the crack propagation, and even few studies deal with the lo- 73 calized crack growth model within a global bridge structure. In reality, fa- 74 tigue crack propagation will change the stiffness and the stress state of the 75 local structural detail which will further affect the crack growth behavior 76 in turn. This interaction problem requires a global-local cracked model of 77 the structure to implement crack propagation analysis, or an isolated local 78 cracked model whose boundary conditions are not affected by local 79 changes in stiffness due to crack propagation.

In the present study, an enhanced fatigue assessment of the critical 81 welded connections in a steel-concrete composite railway bridge, the 82 
Sesia viaduct, was performed by the LEFM based crack propagation analysis through dynamic simulations of the global-local bridge model. The main purpose of this study is to predict the fatigue crack propagation life of the most fatigue-vulnerable welded connections in the bridge, as well as to compare the fatigue life estimated by the LEFM approach and the nominal stress based $S-N$ method in the previous research [1]. In the previous study of the authors [1], a global finite element (FE) model of the Sesia viaduct was built and validated by the in-situ dynamic test results including modal identifications and strain measurements [15]. The dynamic stress histories of the concerned structural details generated by the global FE model of the bridge due to a high-speed train passage were used to calculate the fatigue damage based on the $S-N$ method and then, the most fatigue critical welded connections were identified. As a continuation, in this study, the most fatigue critical connections were built with brick elements, which were incorporated into the global FE model. This FE model is termed as the global-local model of the bridge in the following paragraphs. The SIF histories of the cracks in the critical connections were obtained by global-local dynamic analyses of the bridge, which were used to validate the empirical SIF formulas for the pertinent connections. Then, the fatigue propagation life of each critical connection was predicted using a standard Paris crack growth model based on the validated SIF equations.

\section{Global bridge model and fatigue critical connections}

\subsection{Sesia viaduct and dynamic experiments}

The Sesia viaduct was constructed along a new Italian high-speed railway line connecting Torino with Milano, over the Sesia River near the city of Novara. It is a box-girder steel-concrete composite bridge and consists of seven simply supported spans, each approximately $46 \mathrm{~m}$ long, reaching a total length of $322 \mathrm{~m}$. A general view of the bridge is given in Fig. 1. The double-box steel girder has 13 intermediate and 2 end cross frame diaphragms (see Fig. 2). The bottom steel box made of S355 steel was built by in-situ assembly of three segments, each roughly $15 \mathrm{~m}$ in length, connected by full penetration butt welding. The thickness of the lower flanges in segment $\mathrm{C} 1$ is $25 \mathrm{~mm}$, which is smaller than that in segment $\mathrm{C} 2,30 \mathrm{~mm}$. However, the thickness of the girder webs A, B and C in segment $\mathrm{C} 1,20 \mathrm{~mm}$, is larger than that in segment $\mathrm{C} 2,18 \mathrm{~mm}$. The top concrete slab cast in the field on prefabricated concrete elements is $13.6 \mathrm{~m}$ wide and $0.4 \mathrm{~m}$ thick, and is connected to the upper flanges of the steel box girder by shear studs. On the ballast, two tracks with UIC60 rails are supported by prestressed concrete sleepers at an interval of $0.6 \mathrm{~m}$.

In order to evaluate the dynamic behavior, the actual train loads and the fatigue stress spectra of the bridge, preliminary dynamic experiments and long-term monitoring were carried out on the Sesia viaduct [15-17]. Due to the large scale of the bridge, in-situ measurements were concentrated on the second span from the Torino side. Besides, a small number of accelerometers were placed on the first and third spans to evaluate the dynamic interaction between two adjacent spans. The vertical and/or horizontal accelerations at 89 positions were measured with 33 accelerometers in several different setups, where 7 fixed reference positions including 1 horizontal and 6 vertical acceleration

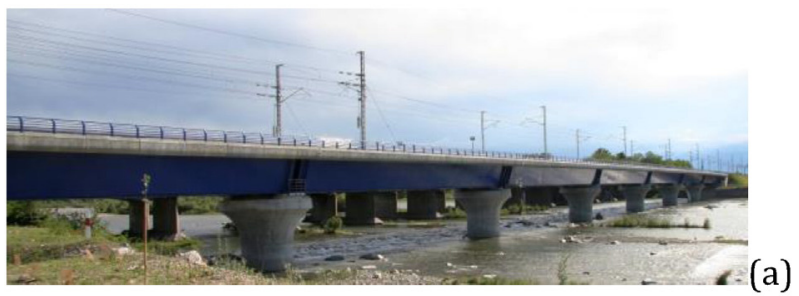

measurements were adopted. A full description and arrangement of ac- 134 celerometers can be found in Ref. [15]. Measurements were performed 135 to obtain acceleration responses of the bridge due to ambient vibrations 136 (excited by wind and traffic load of the adjacent highway) and high- 137 speed train passages. With the vibration data, modal identification of 138 the bridge (eigenfrequencies, damping ratios and mode shapes) was 139 performed by the reference based stochastic subspace identification 140 [18]. Based on the ambient vibration data, a total of 8 modes were iden- 141 tified for the second span, including the first and second bending modes, 142 as well as the first and second torsional modes. According to the mode 143 shapes of the adjacent spans, the identified modes of the second span 144 could be subdivided into symmetrical and anti-symmetrical ones, 145 which revealed that the neighboring spans were dynamically coupled 146 through the ballast layer and the continuous rails. From the free vibra- 147 tion data immediately after the train left the second span, three sym- 148 metrical modes, i.e. the first and second bending modes and the first 149 torsional mode, were extracted. Additionally, the first and second sym- 150 metrical bending modes were also identified through the vibration data 151 during a train crossing the span. Thus, it was concluded that the train 152 passage predominately excited the symmetrical modes. Detailed 153 modal analysis results were described and discussed in Refs. [15,19]. 154

The dynamic strains in the longitudinal direction were measured 155 with the fiber optic strain sensors during a high-speed train passage. 156 These sensors measured the relative displacement between a pair of 157 points at a distance of $1.0 \mathrm{~m}$ on the steel box girder or $1.2 \mathrm{~m}$ on the con- 158 crete sleepers. A total of 16 sensors were installed at Cross Sections 1159 and 5. A schematic plot of the strain sensor arrangement can be found 160 in Ref. [1].

\subsection{Global model of a single span and verification}

162

Due to the large dimensions of the Sesia viaduct including seven 163 spans, a FE model of the complete bridge would lead to expensive com- 164 putational costs. As the seven simply supported spans are identical to 165 each other, a single span model is sufficient and also efficient to estimate 166 the fatigue damage of the bridge. Therefore, a detailed FE model of the 167 second span (as shown in Fig. 3), was built using the general FE software 168 ABAQUS [20], and appropriate boundary conditions were applied at the 169 ends of rails and ballast to simulate the weak coupling between the ad- 170 jacent spans. The steel box girder was modeled by four-node shell ele- 171 ments S4 and the bracings were simulated by beam elements B31 in 172 combination with shell elements S4 at the end connections. Couplings 173 of 6 degree of freedoms (DOFs) were adopted to join the endpoint of 174 beam element with the edge of shell element, at a distance of $0.8 \mathrm{~m} 175$ from the bolt connections of the bracings. The preloaded high- 176 strength bolt connections of the bracings and the gusset plates were as- 177 sumed rigid and realized by the TIE option in ABAQUS [20], which is a 178 surface-based constraint to make all DOFs equal for a pair of surfaces. 179 The concrete deck and safety barrier were modeled by eight-node 180 hexahedral brick elements C3D8. The shear studs were not explicitly 181 modeled and the TIE constraints were used to connect the concrete 182 deck to the upper flanges of the steel box girder. The ballast layer was 183 assumed as a continuum and simulated by brick elements C3D8. The 184

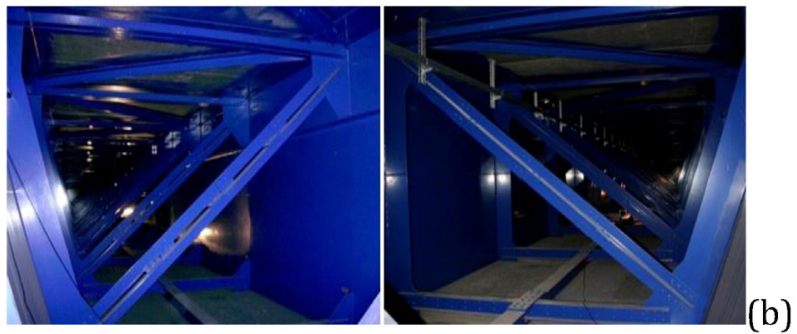

Fig. 1. Sesia viaduct: (a) general view of the spans and (b) interior view of the double-box girder. 


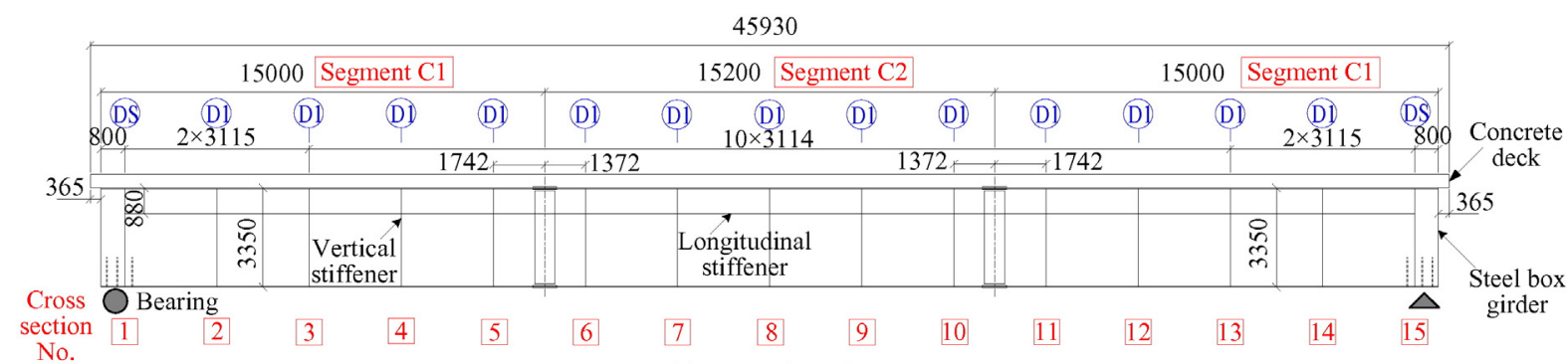

(a) Elevation view

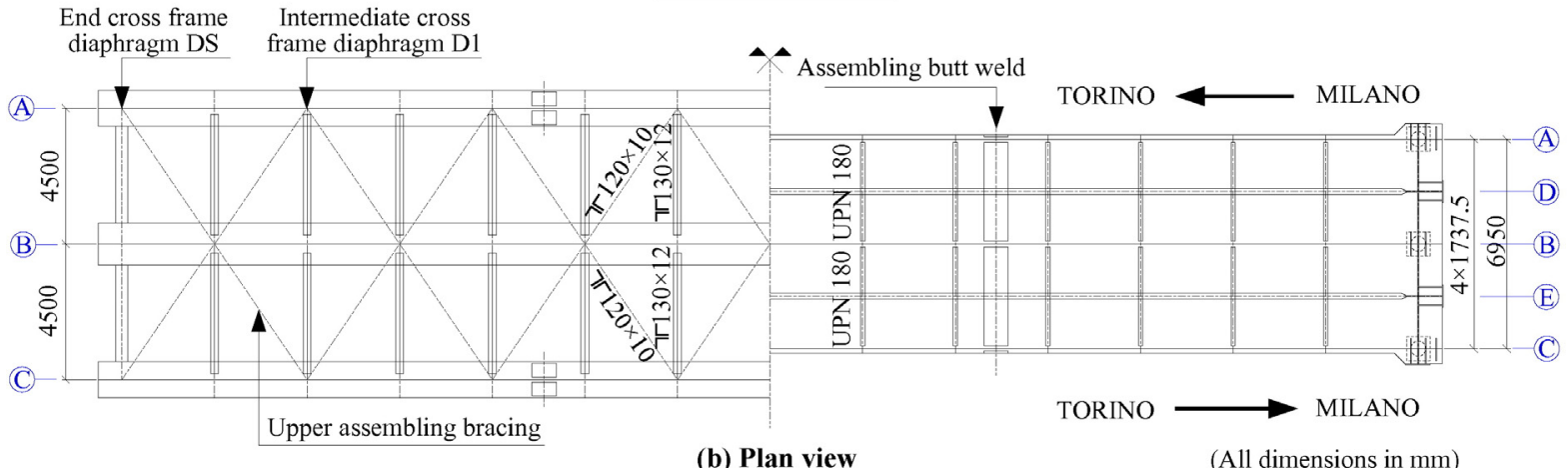

Fig. 2. Layout of a simply supported span of the Sesia viaduct: (a) elevation view and (b) plan view.

global FE model included about 1800 beam elements, 84,000 shell elements and 6400 brick elements, resulting in over 85,500 nodes.

Each railway track model was composed of two beams representing the rails and a series of mass points representing the concrete sleepers. The rail pads that fasten the rails to the sleepers were simulated by springs \& dashpots between the beams and the mass points, with stiffness $K_{\mathrm{rp}}=500 \mathrm{MN} / \mathrm{m}$ and damping coefficient $C_{\mathrm{rp}}=200 \mathrm{kNs} / \mathrm{m}$ [15]. The vertical bending stiffness of the rail is $6.4 \times 10^{6} \mathrm{~N} \cdot \mathrm{m}^{2}$ and the linear density is $60 \mathrm{~kg} / \mathrm{m}$. Symmetrical boundary conditions were used at the ends of rails and ballast layer, as symmetrical modes were predominantly excited by the train passage in the experiments. The bearing system was composed of one unidirectional sliding bearing, two fixed 196 bearings and three bidirectional sliding bearings. At the lower flanges 197 of the steel box girder in the FE model, the corresponding translational 198 DOFs were restrained in accordance with the bearing system as 199 shown in Fig. 3.

200

During the preliminary dynamic tests, there was only one type of 201 high-speed train ETR500Y running on the newly-built railway. There- 202 fore, this particular train ETR500Y was adopted in the FE dynamic sim- 203 ulations of the bridge due to train passages. The axle load scheme of the 204 train ETR500Y could be found in Ref. [1], which was provided by the Ital- 205 ian railway company RFI S.p.A. In the FE analyses, a moving load model, 206

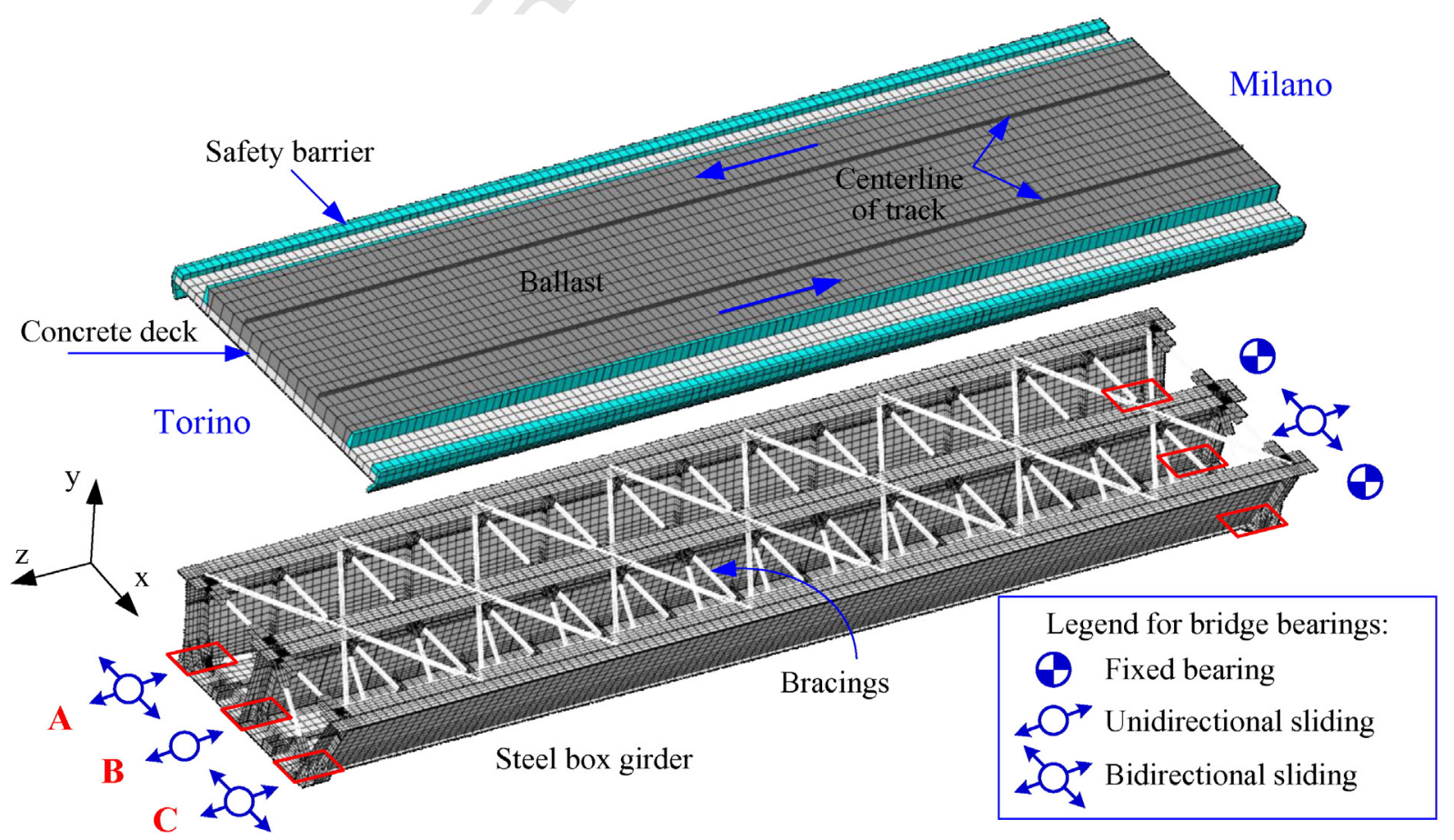

Fig. 3. Global FE model and bearing system of the second span. 
in which the train axles were represented by a series of moving constant forces, was adopted to simulate the train passage through the span. An ABAQUS user subroutine DLOAD [20] coded by FORTRAN was used to realize the moving load model of the train.

The natural frequencies of the bridge span were obtained through modal analysis of the FE model as shown in Fig. 3. In modal identification based on the in-situ measurements, the frequencies were identified from the ambient vibration, the train induced vibration and the free vibration after the train passage, respectively. The frequencies extracted from the ambient vibration data were adopted to validate the accuracy of the FE model in predicting the fundamental dynamic characteristics of the bridge span. The frequencies obtained by FE analysis and identified from the ambient vibration data were in good agreement which was presented in the previous work of the authors [1].

In the dynamic analysis, a structural damping matrix was assumed according to the Rayleigh damping formulation [21], which is proportional to the mass matrix and the stiffness matrix. The mass and stiffness damping coefficients $\alpha$ and $\beta$ can be estimated by two reference frequencies and the associated modal damping ratios. Here, the natural angular frequencies of the first bending and the first torsional modes of the span were adopted as the reference frequencies. An identical modal damping ratio $2.5 \%$ was considered for both reference modes, which was nearly the mean value of all identified modal damping ratios in the tests [1].

In the dynamic experiments, the train ETR500Y was running at a speed of $288 \mathrm{~km} / \mathrm{h}$ from Milano to Torino on the AB-side of the double track railway as indicated by Fig. 3. The dynamic responses of the bridge span during and after the train passage with the actual speed were computed by implicit time integration method in ABAQUS/Standard. Referring to the previous work [1], the correspondence between the measured and simulated acceleration results both in time and frequency domains was reasonably good, which indicated that the dynamic behavior of the bridge span was well represented by the global FE model. The computed time histories of the longitudinal displacements of the nodes corresponding to the positions of the fiber optic sensors were extracted for the strain history calculations. The good agreement in simulated and measured strain history results [1] further validated that the dynamic response due to a high-speed train passage was accurately predicted by the aforementioned global FE model, which could be adopted in subsequent fatigue assessment of the bridge.

\subsection{Fatigue critical connections predicted by $S-N$ method}

The preliminary fatigue assessment of the Sesia viaduct was performed in the previous study of the authors [1] using the traditional $S$ $N$ method, which is based on the structural detail category determined $S-N$ design curve and the nominal stress history applied on the concerned structural detail. Firstly, several structural details of the Sesia viaduct were selected for fatigue evaluation, including welded and bolted connections. The selected structural details were classified into the most relevant fatigue detail categories according to the current design codes, i.e. Eurocode 3 [2], BS 5400 [3] and AASHTO [4]. Each category was specified with a standard $S-N$ curve in each design code. Secondly, dynamic responses of the bridge span due to one passage of the train ETR500Y were simulated by the validated FE model and the nominal stress histories at the concerned structural details were monitored and extracted from the FE analysis results. Thirdly, the variable amplitude stress histories of the structural details were converted into stress range spectra (stress range versus number of cycles) using the Rainflow cycle counting method [22] and then the fatigue damage of each structural detail was calculated based on the Palmgren-Miner [5-6] cumulative damage rule and the design code specified $S-N$ curve. Based on these analyses, a fatigue criticality ranking of each structural detail was obtained and the most fatigue critical connections were identified from all concerned connections of the steel box girder.
Through the preliminary fatigue assessment based on the traditional 270 $S-N$ method, the most fatigue critical connection within each structural 271 detail category was identified in the previous work [1]. Among the cope 272 hole detail as shown in Fig. 4a, CH-A05\&06 on Girder A between Cross 273 Sections 5 and 6 is the most critical connection of all connections of 274 this category in the bridge span. For the assembling butt welds of the 275 three segments of the bridge span, butt weld connection BW-05\&06 276 (Fig. 4b) on the lower flanges of the steel box girder between Cross 277 Sections 5 and 6 is the most fatigue critical. Among the non-load carry- 278 ing fillet welds of the transverse stiffeners attached to the lower flanges 279 of the steel girders, ST-A05 (Fig. 4c) of Girder A at Cross Section 5 is the 280 most critical connection all through the span. Of all load carrying fillet 281 welds around the gusset plates of the bracings, connection FW-15W8 282 (Fig. 4d) at Cross Section 15 on the transverse stiffener of Girder $C$ is pre- 283 dicted to be the most fatigue critical. In these welded connections, weld 284 defects, such as welding cracks, lack of fusion, incomplete penetration, 285 inclusions, undercuts and so on, may be unavoidable. In case of such 286 conditions, the traditional S- $N$ method may not be able to quantitatively 287 evaluate the effect of weld defects on the fatigue life. Therefore, a further 288 fatigue assessment of these critical welded connections is performed by 289 fatigue crack propagation analysis based on the LEFM approach in the 290 following sections.

\section{Cracked welded details and stress intensity factor}

\subsection{Empirical solution for stress intensity factor}

Fatigue failure is a process that involves two stages of damage, i.e. 294 crack initiation and crack propagation. In welded connections, the fa- 295 tigue crack initiation life is generally quite short and could be neglected, 296 as welded details probably include small crack-like defects, such as lack 297 of fusion, inclusions, undercuts and so on. Therefore, the total fatigue life 298 of a welded detail could be assumed as a function of the crack propaga- 299 tion life [23]. In crack propagation analysis based on the empirical Paris 300 law [24], the controlling parameter, i.e. the stress intensity factor (SIF) 301 range $\Delta K$, needs to be determined. According to the locations, shapes 302 and sizes of the crack-like flaws that might exist in the welded details 303 of the Sesia viaduct, simplified crack models with through edge crack, 304 semi-elliptical surface crack and central through crack were assumed 305 for the critical welded connections and the empirical formulas for SIF 306 calculations were obtained by modifications of the theoretical crack 307 models.

For mode I crack, corresponding to in-plane tensile crack opening, 309 the SIF for arbitrary loading may be expressed in the following general 310 form [8]:

$K_{\mathrm{I}}=Y \sigma \sqrt{\pi \mathrm{a}}$

where, $Y$ is a geometry correction factor and depends on the crack con- 313 figuration and the type of loading; $\sigma$ is the remotely applied stress; and $a$ is the crack size.

For a semi-elliptical surface crack in a finite width plate subjected to 315 tension as shown in Fig. 5, an empirical solution for SIF was given by 316 Newman and Raju [25-26] as follows:

$K_{\mathrm{I}}=Y \sigma \sqrt{\pi \mathrm{a}}=M_{\mathrm{k}} f_{\mathrm{w}} \sigma \sqrt{\pi \mathrm{a}}$

where, the geometry correction factor $Y$ is decomposed into $M_{\mathrm{k}}$ and $f_{\mathrm{w}} ; 319$ $M_{\mathrm{k}}$ is the stress magnification factor given by Eq. (3); $f_{\mathrm{w}}$ is the finite width correction factor given by Eq. (10); and $a$ is the crack depth as 320 shown in Fig. 5.

$M_{\mathrm{k}}=\left[M_{1}+M_{2}\left(\frac{a}{t}\right)^{2}+M_{3}\left(\frac{a}{t}\right)^{4}\right] g f_{\phi} / Q$ (3) 

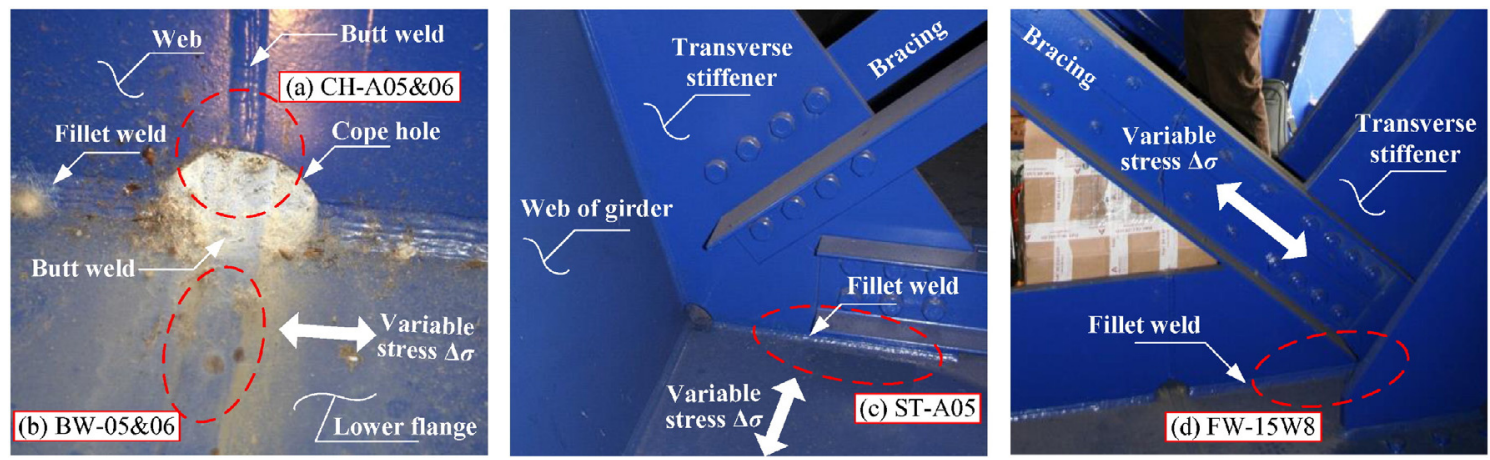

Fig. 4. Close-up views and details of the fatigue critical connections identified by the traditional S-N method: (a) CH-A05\&06; (b) BW-05\&06; (c) ST-A05 and (d) FW-15W8.

where,

$M_{1}=1.13-0.09\left(\frac{a}{c}\right)$

$M_{2}=-0.54+\frac{0.89}{0.2+(a / c)}$

$M_{3}=0.5-\frac{1}{0.65+(a / c)}+14\left(1-\frac{a}{c}\right)^{24}$

$g=1+\left[0.1+0.35\left(\frac{a}{t}\right)^{2}\right](1-\sin \phi)^{2}$

$f_{\phi}=\left[\left(\frac{a}{c}\right)^{2} \cos ^{2} \phi+\sin ^{2} \phi\right]^{1 / 4}$

$Q=\left[1+1.464\left(\frac{a}{c}\right)^{1.65}\right]^{1 / 2}$

$f_{\mathrm{w}}=\left[\sec \left(\frac{\pi \mathrm{c}}{2 W} \sqrt{\frac{a}{t}}\right)\right]^{1 / 2}$.

In Eqs. (2) to (10), the definitions of the geometries $W, t, a, c$ and $\phi$ are shown in Fig. 5 and the formulas are effective only when the following conditions are satisfied, i.e. $0<a / c \leq 1.0,0 \leq a / t<1.0, c / W<0.5$ and $0 \leq \phi \leq \pi$.

The steel box girder of each bridge span was constructed by in-situ assembly of three segments connecting by complete joint penetration
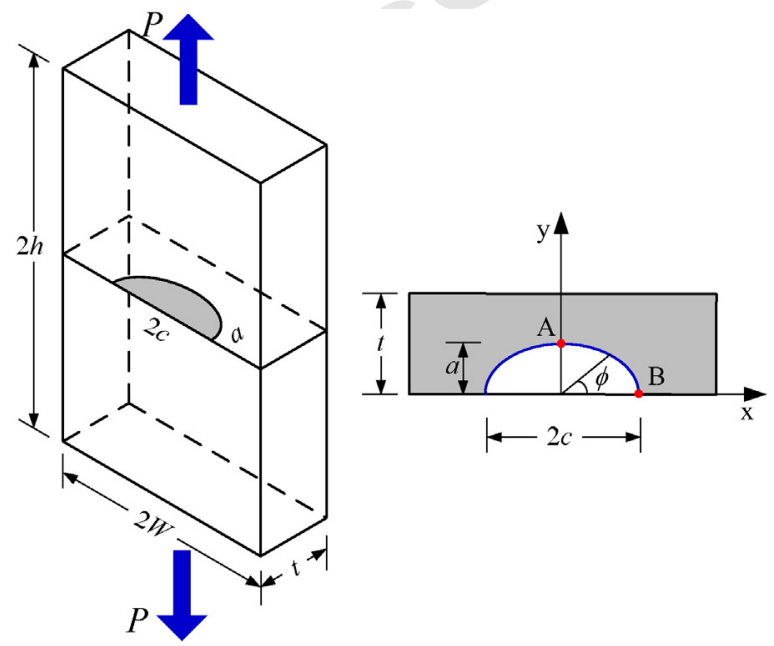

Fig. 5. Stress intensity factor SIF calculation for a semi-elliptical surface crack in a finite plate subjected to combined tension and bending. butt welding. For the fatigue critical connection BW-05\&06 at the 349 lower flange of the steel box girder between Cross Sections 5 and 6 (re- 350 ferring back to Fig. 4b), a semi-elliptical surface crack model (shown in 351 Fig. 6) is assumed for the butt weld connection. In consideration of the 352 local stress concentration raised by the geometric irregularity of the 353 butt weld, the SIF magnification factor $M_{\mathrm{km}}$ is introduced by the British 354 Standard BS 7910 [27] to modify the Newman-Raju solution given in 355 Eq. (2) by multiplication. For point A at the crack front shown in Fig. 6, 356 the expression of the SIF magnification factor $M_{\mathrm{km}}$ for tension is given 357 by Eq. (11) [27]:

$M_{\mathrm{km}}=u_{1}\left(\frac{a}{t}\right)^{k_{1}}$

where, $a$ is the crack depth; $t$ is the plate thickness; parameters $u_{1}$ and $k_{1}$ are given in BS 7910 [27], which are related to the crack depth 361 $a$ and the weld geometries, i.e. the butt weld width $L$ and the plate thick- 362 ness $t$.

In the Sesia viaduct, transverse stiffeners were attached to the steel 364 box girders by fillet welding. For the fatigue critical connection ST-A05 365 on Girder A at Cross Section 5 (referring back to Fig. 4c), a semi- 366 elliptical surface crack is assumed in the lower flange near the fillet 367 weld toe of the transverse stiffener as shown in Fig. 7. The SIF magnifi- 368 cation factor $M_{\mathrm{km}}$ is included to modify the Newman-Raju solution by 369 multiplication, so as to take the geometric effect of the fillet weld into 370 account. For point $A$ at the deepest position of the surface crack, the ex- 371 pression of the SIF magnification factor $M_{\mathrm{km}}$ is given as follows [28]: $\quad 372$

$M_{\mathrm{km}}=u_{2}\left(\frac{a}{t}\right)^{k_{2}}$

where,

$u_{2}=0.8068-0.1554\left(\frac{v}{t}\right)+0.0429\left(\frac{v}{t}\right)^{2}+0.0794\left(\frac{w}{t}\right)$

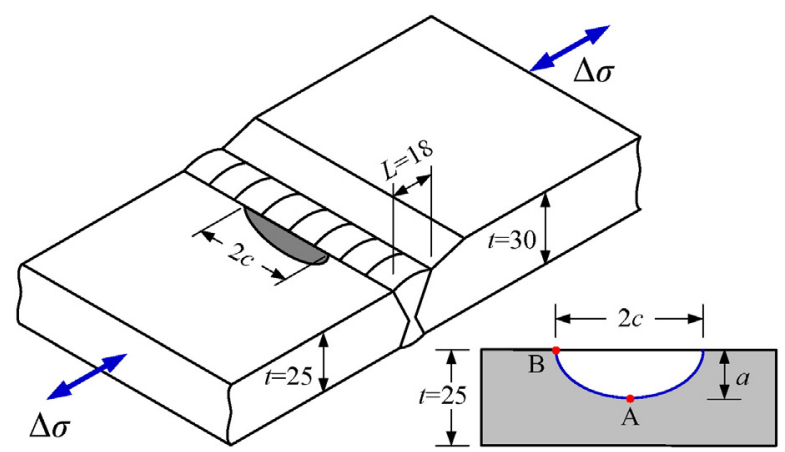

Fig. 6. A semi-elliptical toe crack model for the butt weld connection at the lower flange of the steel box girder. 


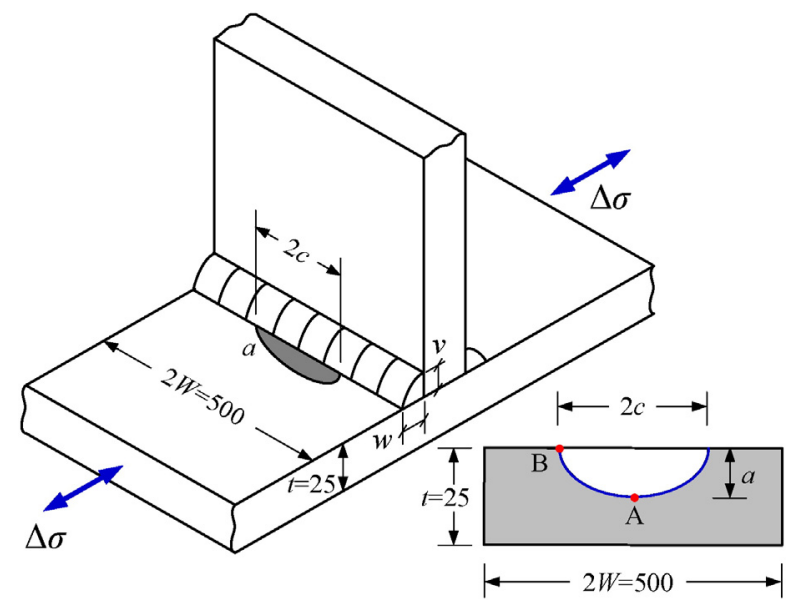

Fig. 7. A semi-elliptical surface crack model for the fillet weld connection of the transverse stiffener.

$k_{2}=-0.1993-0.1839\left(\frac{v}{t}\right)+0.0495\left(\frac{v}{t}\right)^{2}+0.0815\left(\frac{w}{t}\right)$

where, $v$ and $w$ are the vertical height and the width of the fillet weld as shown in Fig. 7; and $t$ is the plate thickness of the lower flange of the steel box girder.

In assembly of the three segments of the steel box girder, cope holes were drilled in the web-flange transition regions to allow continuous butt welding of the flanges and to eliminate the triple point welds. For the fatigue critical connection $\mathrm{CH}-\mathrm{A} 05 \& 06$ on Girder A at Cross Sections 5 and 6 (referring back to Fig. 4a), a through edge crack is assumed in the butt weld connection at the apex of the cope hole as shown in Fig. 8. In this case, the general SIF equation given in Eq. (1) can be further rewritten as follows [9,29]:

$K_{\mathrm{I}}=Y \sigma \sqrt{\pi \mathrm{a}}=M_{\mathrm{k}} M_{\mathrm{km}} \sigma \sqrt{\pi \mathrm{a}}$

where,

$M_{\mathrm{k}}=1.1216+6.52\left(\frac{a}{W}\right)^{2}-12.39\left(\frac{a}{W}\right)^{4}+89.06\left(\frac{a}{W}\right)^{6}-188.61\left(\frac{a}{W}\right)^{8}$

392
$M_{\mathrm{km}}=1.3793\left(\frac{a}{R}\right)^{-0.2627}$

where, $R$ is the radius of the cope hole.

In the load carrying fillet welds around the gusset plates of the diagonal bracings, FW-15W8 at the bridge bearing near Girder C (referring back to Fig. 4d) is the most fatigue critical connection and a root crack representing the incomplete penetration is modeled for the fillet weld 398 connection, as shown in Fig. 9. For tensile loading perpendicular to the fil- 399 let weld, the SIF solution for the root crack tip A is given as follows [27]: 400

$$
K_{\mathrm{I}}=Y \sigma \sqrt{\pi \mathrm{a}}=M_{\mathrm{k}} f_{\mathrm{wm}} \sigma \sqrt{\pi \mathrm{a}} .
$$

The influence of joint geometry on the SIF for a root flaw in a fillet weld is accounted for by the application of the modified finite width 403 correction factor $f_{\mathrm{wm}}$ given in Eq. (19) and the stress magnification fac- 404 tor $M_{\mathrm{k}}$ given by Eq. $(20)[27,30]$.

$$
\begin{aligned}
& f_{\mathrm{wm}}=\sqrt{\sec \left[\frac{\pi}{2}\left(\frac{2 a}{W}\right)\right]} \\
& M_{\mathrm{k}}=\lambda_{0}+\lambda_{1}\left(\frac{2 a}{W}\right)+\lambda_{2}\left(\frac{2 a}{W}\right)^{2}
\end{aligned}
$$

where,

$$
\lambda_{0}=0.956-0.343\left(\frac{h_{\mathrm{f}}}{B}\right)
$$

$\lambda_{1}=-1.219+6.210\left(\frac{h_{\mathrm{f}}}{B}\right)-12.220\left(\frac{h_{\mathrm{f}}}{B}\right)^{2}+9.704\left(\frac{h_{\mathrm{f}}}{B}\right)^{3}-2.741\left(\frac{h_{\mathrm{f}}}{B}\right)^{4}$

$\lambda_{2}=1.954-7.938\left(\frac{h_{\mathrm{f}}}{B}\right)+13.299\left(\frac{h_{\mathrm{f}}}{B}\right)^{2}-9.541\left(\frac{h_{\mathrm{f}}}{B}\right)^{3}+2.513\left(\frac{h_{\mathrm{f}}}{B}\right)^{4}$.

In Eqs. (31) to (23), the definitions of the geometries are shown in Fig. 9 and the ranges of application are as follows, $0.1 \leq 2 a / W \leq 0.7419$ and $0.2 \leq h_{\mathrm{f}} / B \leq 1.2$.

\subsection{Stress intensity factor calculated by global-local FE model}

As the configurations of the fatigue critical connections shown in 422 Fig. 4 are somewhat complicated, the stress fields around the connec- 423 tions are not uniformly distributed. This makes difficulty in the determi- 424 nation of the nominal stresses. Furthermore, the exact location of the 425 crack plays an important role in calculation of the SIF at the crack 426 front. Therefore, a refined local model for each fatigue critical connec- 427 tion containing an initial crack was incorporated into the global FE 428 model described in Section 2.2. The SIF histories of the crack front 429 were calculated directly through dynamic analysis of the global-local 430 cracked FE model of the bridge span. These results are used to validate 431

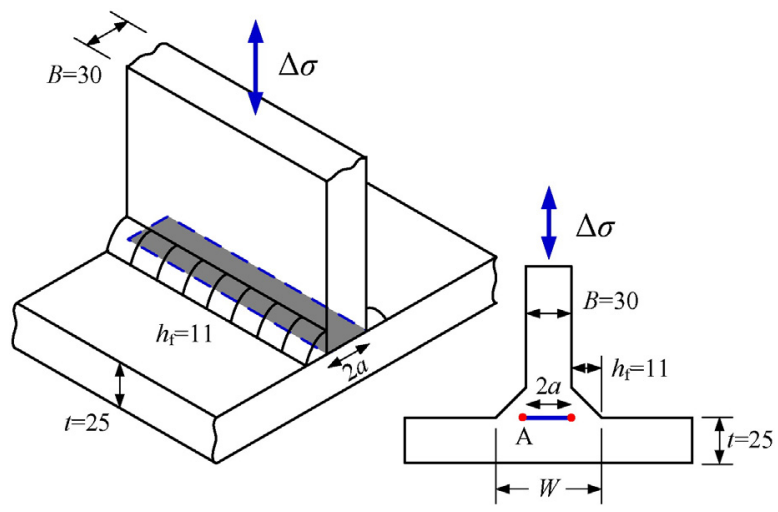

Fig. 9. A root crack model for fillet weld connection around the gusset plate of the diagonal bracing.

Fig. 8. A through edge crack model for the butt weld connection at the apex of a cope hole. 
the applicability and the accuracy of the empirical formulas for SIF solutions of cracks in the critical welded details.

As shown in Fig. 10, the fatigue critical connections identified by the $\mathrm{S}-\mathrm{N}$ method, i.e. the cope hole detail $\mathrm{CH}-\mathrm{A} 05 \& 06$, the butt weld connection BW-05\&06, the fillet weld attachment detail ST-A05 and the load carrying fillet weld connections FW-01W2, FW-01W8, FW-15W2 and FW-15W8, were refined with three-dimensional brick elements and incorporated into the global shell model of the steel box girder. The local cracked model with brick elements was connected to the global shell element model by the SHELL-TO-SOLID COUPLING constraints [20] in ABAQUS. The geometry of the crack was modeled according to the configuration given by Figs. 6 to 9. The detailed FE meshes of the cracked welded connections are shown in Fig. 11.

As shown in Fig. 11a, a through edge crack with a crack depth of $a$, was introduced into the butt weld at the apex of the cope hole. Through the web thickness, 4 elements were meshed. Around the crack front, 7 contours were considered, adopting 24 elements in each of them. As shown in Fig. 11b, a semi-elliptical surface crack (with the width $2 c$ and the depth $a$ ) was included at the toe of the assembling butt weld on the lower flange of the steel box girder and the crack center was situated at a distance of $680 \mathrm{~mm}$ from the web, where the largest longitudinal stress of the butt weld was sustained. As the connection $\mathrm{CH}$ A05\&06 and BW-05\&06 were located at the lower flange of the steel box girder near the midspan, the associated through edge crack and semi-elliptical surface crack were primarily in mode I (opening) tensile loading. The refined local crack models, as shown in Fig. 11a and b, contained more than 19,000 brick elements, including hexahedral elements C3D8, wedge elements C3D6 and tetrahedral elements C3D4.

As shown in Fig. 11c, a semi-elliptical surface crack (with the width $2 c$ and the depth $a$ ) was inserted into the fillet weld toe near the edge of the transverse stiffener where the largest longitudinal stress was predicted by the global shell element model. The semi-elliptical surface crack was mainly in mode I loading, as the connection ST-A05 was also located at the lower flange close to the midspan of the simply supported bridge span. The refined local FE model as shown in Fig. 11c consisted of 11,000 brick elements.

As shown in Fig. 11d, central through cracks (i.e. fillet weld root cracks) were modeled to simulate the incomplete penetration gaps between the gusset plates of the diagonal bracings and the lower flanges of the steel box girder. Four such connections at the bridge bearings (shown in Fig. 10), i.e. connections FW-01W2, FW-01W8, FW-15W2 and FW-15W8, were refined with local crack models and each local model contained 20,000 brick elements. When the train runs on the 474 FW-15W2 to FW-01W2 side as indicated by Fig. 10, the diagonal brac- 475 ings of this side are in compression and the fillet weld root cracks of 476 the associated gusset plates are closed, while the diagonal bracings of 477 the other side are in tension and the corresponding cracks are open. 478 Those can be reflected by the SIF results of the crack fronts in the subse- 479 quent $\mathrm{FE}$ analyses.

s the above mentioned cracks were carried out in 4 the INTERACTION MODULE (special $\rightarrow$ crack) [20] in ABAQUS/CAE and 482 the contour integrals around the crack fronts were calculated to evalu- 483 ate the SIF, which were defined by the history output request in the 484 STEP MODULE [20]. Dynamic responses of the bridge span due to the 485 train ETR500Y passage were re-computed through the global-local FE 486 model and the SIF histories of the crack fronts were obtained for each 487 cracked welded connection. The SIF results indicate that: (a) for connec- 488 tion BW-05\&06 and ST-A05, the largest value is at the deepest point of 489 the semi-elliptical surface crack; (b) for connection CH-A05\&06, the 490 largest value appears at the center of the through edge crack; and 491 (c) for connection FW-15W8, SIF varies along the crack front as the 492 stress distributes nonuniformly along the fillet weld. The computed 493 time histories of the maximum mode I stress intensity factor $K_{\mathrm{I}}$ around 494 the crack front of each crack with a certain size $a$ and aspect ratio $a / c$ are 495 presented in Fig. 12.

It is well known that the crack size is relatively small in the earlier 497 stage of crack propagation but obviously affects the fatigue crack prop- 498 agation life. Therefore, relatively small crack sizes, i.e. $a=0.2,1.0$ and 499 $5.0 \mathrm{~mm}$, were selected to validate the empirical SIF solutions using the 500 global-local FE analyses. For a semi-elliptical initial flaw at the weld 501 toe, an aspect ratio $a / c=0.2$ is recommended by the British Standard 502 BS 7608 [31] and thus, was adopted in the present validation analyses. 503 Comparisons between the empirical solutions and the global-local FE 504 analyses for the SIF calculations are given in Table 1 , where $K_{\mathrm{I}, \mathrm{emp}}$ is cal- 505 culated by the empirical formulas using the maximum nominal stress 506 $\sigma_{\max }$ of the fatigue critical connection, which was generated by the dy- 507 namic analysis of the global shell element model, and $K_{\mathrm{I}, \mathrm{FEM}}$ is the largest 508 SIF value along the crack front from the entire loading history, which 509 was obtained directly by the dynamic analysis of the proposed global- 510 local cracked FE model. As indicated by Table 1, the error between the 511 empirical solution and the global-local FE model calculation in SIF, 512 ranges from $-10.5 \%$ to $+9.2 \%$, which is probably due to the differences 513 between the nominal stress calculated by the global FE model and the 514 real stress field analyzed by the present global-local FE model. In 515

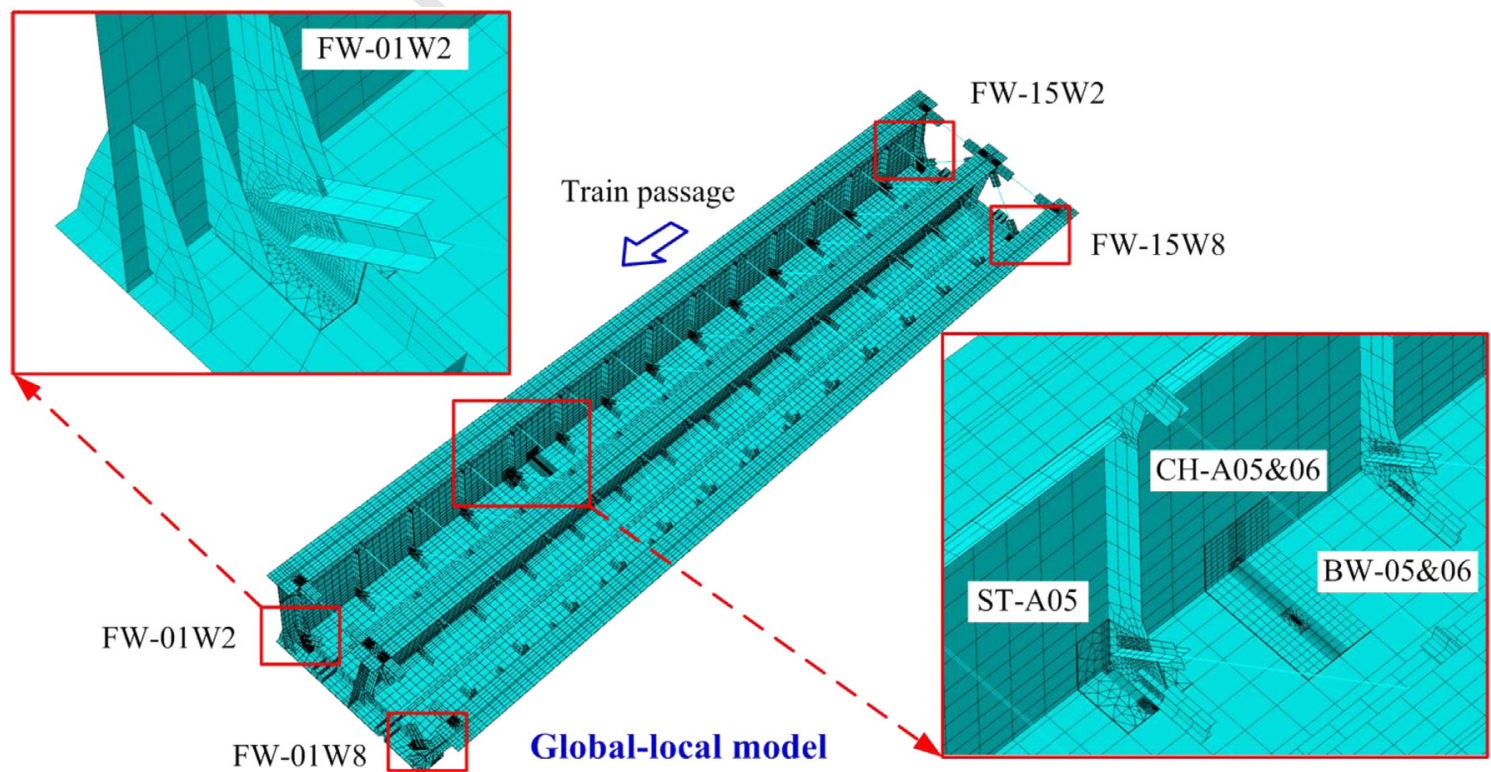

Fig. 10. Global-local FE model of the second span of the Sesia viaduct. 


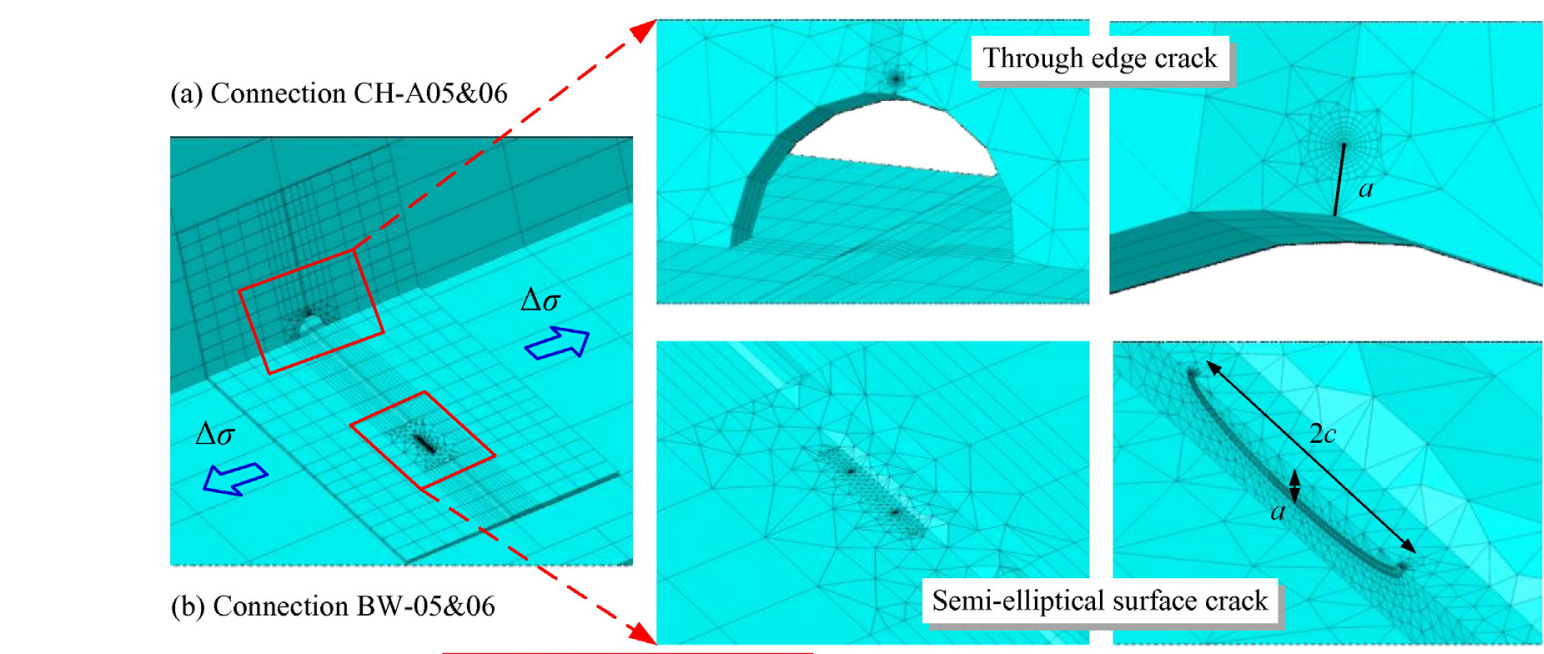

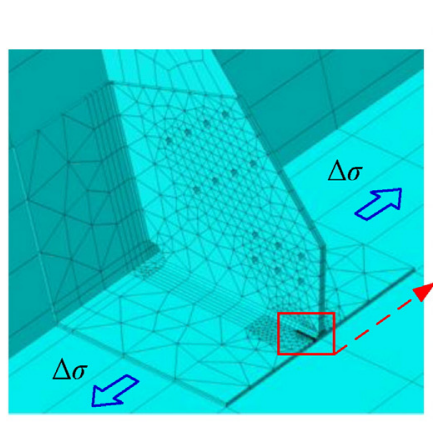

(c) Connection ST-A05

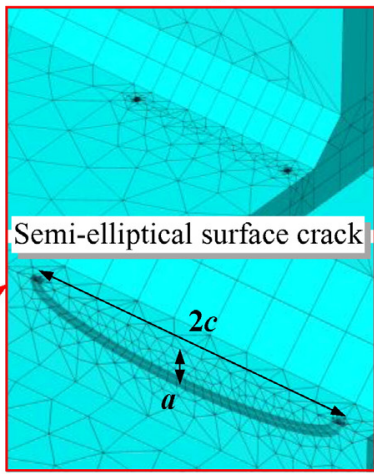

Fig. 11. Local crack models: (a) CH-A05\&06; (b) BW-05\&06; (c) ST-A05 and (d) FW-15W8 general, an acceptable agreement is achieved between the empirical solutions and the global-local FE model analyses, which validates the applicability and the accuracy of the empirical SIF solutions for the cracked welded connections.

\section{Fatigue crack propagation analysis}

\subsection{Material properties, initial and critical crack size}

In the steel box girder of the Sesia viaduct, structural steel S355J2 was adopted when the plate thickness was less than $40 \mathrm{~mm}$, while S355K2 was applied when the thickness exceeded $40 \mathrm{~mm}$. The plate thickness in the aforementioned fatigue critical connections ranged from $18 \mathrm{~mm}$ to $30 \mathrm{~mm}$, thus, according to the steel products standard EN 10025 [32], the yield strength $f_{\mathrm{y}}$ and the ultimate tensile strength $f_{\mathrm{u}}$ of the structural steel S355J2 were $355 \mathrm{MPa}$ and $510 \mathrm{MPa}$, respectively, and the minimum Charpy V-notch impact energy $A_{\mathrm{kv}}$ at $-20^{\circ} \mathrm{C}$ was 27 joules. Because of missing the test data of the material fracture toughness, an empirical correlation as shown in Eq. (24), recommended by BS 7910 [27], was used to estimate the fracture toughness of the structural steel S355J2 by the minimum Charpy energy:

$K_{\mathrm{mat}}=\left[\left(12 \sqrt{A_{\mathrm{kv}}}-20\right)(25 / t)^{0.25}\right]+20$

where, $K_{\mathrm{mat}}$ (in $\mathrm{MPa} \cdot \mathrm{m}^{1 / 2}$ ) is the estimated fracture toughness; $A_{\mathrm{kv}}$ (in joules) is the lower bound Charpy V-notch impact energy at the service temperature; and $t$ (in $\mathrm{mm}$ ) is the thickness of the material for which an estimate of $K_{\text {mat }}$ is required.

The fatigue life of the studied critical welded connections based on the crack propagation analysis was determined using a crack growth relationship proposed by Paris and Erdogan [24], known as the Paris law. The Paris law parameters $C=2.1111 \times 10^{-15} \mathrm{MPa} \cdot \mathrm{mm}^{1 / 2}$ and $m=$

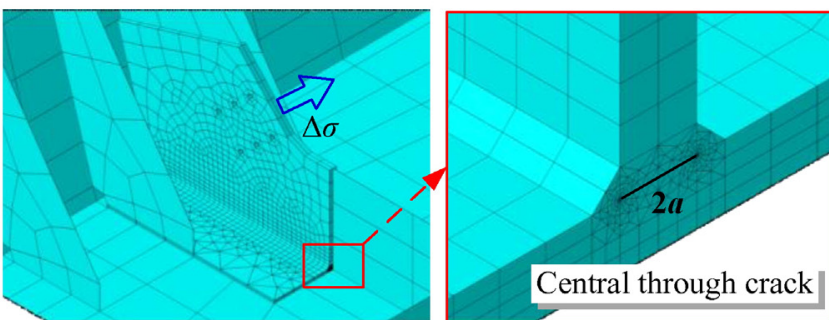

(d) Connection FW-15W8
3.74 in this study were defined after the fatigue crack growth rate 542 tests on steel S355 performed by De Jesus et al. [33], which were the av- 543 erage results of the three test series with different stress ratios $R_{\sigma}=544$ $0.25,0.50$ and 0.75 . The threshold stress intensity factor range, 545 $\Delta K_{\mathrm{th}}=63 \mathrm{MPa} \cdot \mathrm{mm}^{1 / 2}$, given by BS 7910 [27], was applied in the 546 crack propagation analyses of the critical welded connections in this 547 study.

The initial crack size and shape are important parameters in crack 549 propagation analysis and will highly affect the outcome of the remaining 550 fatigue life estimation. In the existing steel structures, non-destructive in- 551 spection, such as ultrasonic test, is generally accepted as a reliable way to 552 determine the size, shape and location of the initial flaw. When flaws or 553 cracks haven't been detected by ultrasonic test, the initial crack size 554 may be assumed conservatively according to the maximum detection 555 ability of the equipment. The non-destructive inspection data of the 556 Sesia viaduct were unavailable and therefore initial cracks were intro- 557 duced by reasonable assumptions. As given in Table 2, the initial crack 558 size and shape of the studied critical welded connections were assumed 559 according to the similar welded details in literatures. When the actual 560 crack size cannot be determined in the welded details, a reasonable as- 561 sumed initial size $a_{0}$, ranging from 0.1 to $0.25 \mathrm{~mm}$, is recommended by 562 BS 7608 [31]. A certain crack size $a_{0}=0.15 \mathrm{~mm}$ is recommended by 563 the International Institute of Welding [34]. From the perspective of 564 LEFM, El Haddad et al. [35] proposed a model to express the threshold 565 stress intensity factor range $\Delta K_{\text {th }}$ using the fatigue limit stress range 566 $\Delta \sigma_{\mathrm{D}}$ and a fictitious initial crack $a_{0}$. Therefore, a fictitious crack length 567 could be estimated as follows:

$a_{0}=\frac{1}{\pi}\left(\frac{\Delta K_{\mathrm{th}}}{Y \cdot \Delta \sigma_{\mathrm{D}}}\right)^{2}$

where, $Y$ is an all-including geometry correction factor, which can be cal- 570 culated for each crack model according to the equations given in 

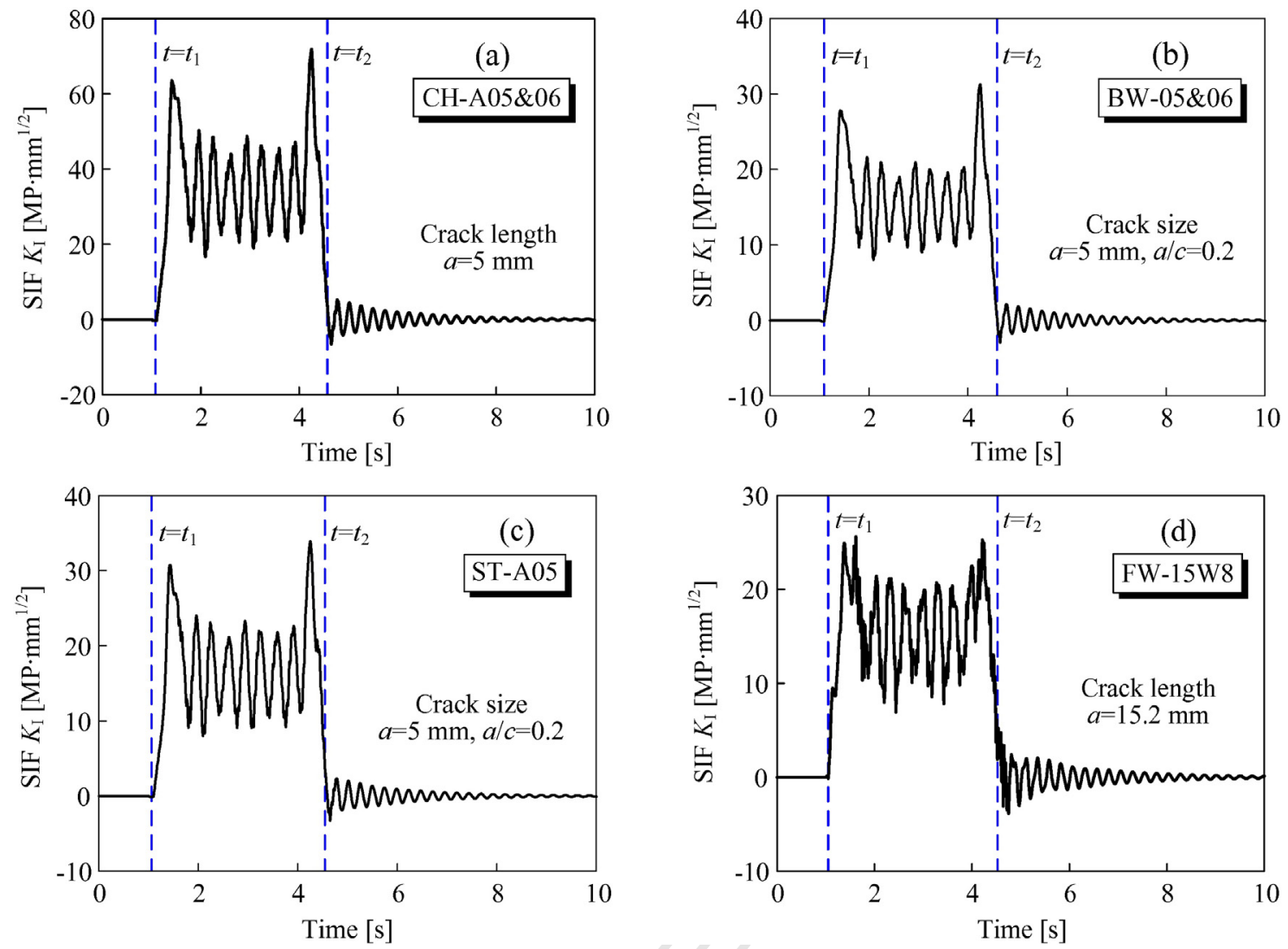

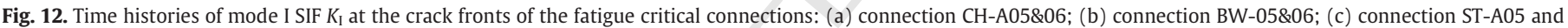
(d) connection FW-15W8.

Section 3.1; and $\Delta \sigma_{\mathrm{D}}$ is the constant amplitude fatigue limit of a detail category, prescribed in Eurocode 3 [2].

In the present study, several initial crack sizes $a_{0}=0.1,0.15,0.2$ and $0.25 \mathrm{~mm}$ were assumed respectively for the semi-elliptical surface cracks in connections BW-05\&06 and ST-A05, and also for the through edge crack in connection $\mathrm{CH}-\mathrm{A} 05 \& 06$, so as to estimate the fatigue crack propagation life taking the initial crack size effects into account. Available inspection data for the aspect ratio $a / c$ of semi-elliptical crack are very limited and also show large variations, as given in Table 2. As recommended by BS 7608 [31], an initial aspect ratio $a /$ $c=0.2$ was adopted for the semi-elliptical surface cracks, kept constant in crack propagation analysis for simplification. For the load carrying fillet weld connection FW-15W8, the incomplete penetration size equaling to the thickness of the gusset plate, $30 \mathrm{~mm}$, should be included in the total crack size and thus, the initial half size of the central through crack was $\left(15+a_{0}\right)$ in which $a_{0}$ was $0.1,0.15,0.2$ and $0.25 \mathrm{~mm}$ as assumed.

Another important parameter for crack propagation analysis is the final critical crack size, which could be estimated by the fracture mechanics based criterion and the serviceability limit state of the structural components. The critical crack size $a_{\mathrm{f}}$ at fracture for each welded con- 591 nection given in Table 2 was determined by the LEFM $K$ criterion as fol- 592 lows:

$a_{\mathrm{f}}=\frac{1}{\pi}\left(\frac{K_{\mathrm{mat}}}{Y \cdot \sigma_{\max }}\right)^{2}$

where, $K_{\text {mat }}$ is the estimated material fracture toughness associated 595 with the plate thickness; and $\sigma_{\max }$ is the maximum nominal stress produced by dead and live loads. Conservatively, a tensile residual stress 596 $0.4 f_{\mathrm{y}}$ is included.

In addition, the crack size should not exceed the serviceability limit 598 state of the structural components and generally, the thickness of the 599 steel plate (in which the crack was detected or assumed) was consid- 600 ered as the maximum allowable crack size $a_{\max }$, given in Table 2. Be- 601 sides, the weld throat size was chosen as the maximum allowable 602 crack extension size of the fillet weld root crack in connection FW- 603 15W8. Lastly, the relative small crack size determined by the LEFM $\mathrm{K}$ cri- 604 terion and the serviceability limit state was adopted as the final critical 605 size, i.e. $a_{\mathrm{cr}}=\min \left(a_{\mathrm{f}}, a_{\max }\right)$.

Table 1

Comparisons between empirical formulas and global-local FE model in SIF calculations.

\begin{tabular}{|c|c|c|c|c|c|c|c|c|c|c|}
\hline \multirow{2}{*}{$\begin{array}{l}\text { Critical } \\
\text { connection }\end{array}$} & \multirow{2}{*}{$\begin{array}{l}\sigma_{\max } \\
{[\mathrm{MPa}]}\end{array}$} & \multicolumn{3}{|c|}{$a=0.2 \mathrm{~mm}$} & \multicolumn{3}{|c|}{$a=1.0 \mathrm{~mm}$} & \multicolumn{3}{|c|}{$a=5.0 \mathrm{~mm}$} \\
\hline & & ${ }^{\mathrm{b}} K_{\mathrm{I}, \mathrm{emp}}$ & ${ }^{\mathrm{b}} K_{\mathrm{I}, \mathrm{FEM}}$ & $\overline{{ }^{c} \text { Error }}$ & $\overline{K_{\mathrm{I}, \mathrm{emp}}}$ & $K_{\mathrm{I}, \mathrm{FEM}}$ & Error & $K_{\mathrm{I}, \mathrm{emp}}$ & $K_{\mathrm{I}, \mathrm{FEM}}$ & Error \\
\hline $\mathrm{CH}-\mathrm{A} 05 \& 06$ & 6.87 & 35.9 & 33.4 & $+7.5 \%$ & 52.6 & 48.9 & $+7.6 \%$ & 77.2 & 71.9 & $+7.4 \%$ \\
\hline BW-05\&06 & 7.48 & 13.1 & 12.0 & $+9.2 \%$ & 17.8 & 16.4 & $+8.5 \%$ & 34.0 & 31.2 & $+9.0 \%$ \\
\hline ST-A05 & 6.36 & 13.0 & 13.6 & $-4.4 \%$ & 19.9 & 20.9 & $-4.8 \%$ & 32.3 & 33.7 & $-4.2 \%$ \\
\hline${ }^{\mathrm{a}} \mathrm{FW}-15 \mathrm{~W} 8$ & 3.03 & 23.6 & 25.6 & $-7.8 \%$ & 25.3 & 27.8 & $-9.0 \%$ & 38.3 & 42.8 & $-10.5 \%$ \\
\hline
\end{tabular}

a The half crack size of the central through crack in the fillet weld connection FW-15W8 is $(a+15) \mathrm{mm}$

b The unit of $K_{\mathrm{I}, \mathrm{emp}}$ and $K_{\mathrm{I}, \mathrm{FEM}}$ is in $\mathrm{MPa} \cdot \mathrm{mm}^{1 / 2}$.

c The error between empirical solution and FE model calculation in SIF is defined as Error $=\left(K_{\mathrm{I}, \mathrm{emp}}-K_{\mathrm{I}, \mathrm{FEM}}\right) / K_{\mathrm{I}, \mathrm{FEM}} \times 100 \%$. 
Table 2

Initial and critical sizes of the assumed cracks in the concerned welded connections.

\begin{tabular}{|c|c|c|c|c|c|c|c|}
\hline \multirow{2}{*}{$\begin{array}{l}\text { Critical } \\
\text { connection }\end{array}$} & \multirow{2}{*}{$\begin{array}{l}\text { Fatigue limit } \\
\Delta \sigma_{\mathrm{D}}[\mathrm{MPa}]\end{array}$} & \multirow{2}{*}{ Crack model } & \multicolumn{2}{|c|}{ Initial crack size $a_{0}[\mathrm{~mm}]$} & \multicolumn{2}{|c|}{$\underline{\text { Critical crack size } a_{\mathrm{cr}}[\mathrm{mm}]}$} & \multirow{2}{*}{$\begin{array}{l}\text { Aspect } \\
\text { ratio } a / c\end{array}$} \\
\hline & & & Literature & Fictitious & $K$ criterion $a_{\mathrm{f}}$ & Serviceability $a_{\max }$ & \\
\hline $\mathrm{CH}-\mathrm{A} 05 \& 06$ & 52.3 & Through edge & $0.1[9]$ & 0.011 & 11.6 & 20 & - \\
\hline BW-05\&06 & 66.3 & Semi-elliptical & $0.2[9]$ & 0.035 & 19.5 & 25 & $0.01[9]$ \\
\hline ST-A05 & 59.0 & Semi-elliptical & $0.125[36]$ & 0.036 & 20.2 & 25 & $0.39[36]$ \\
\hline FW-15W8 & 26.5 & Central through & \multicolumn{2}{|c|}{ Half size $\left(15+a_{0}\right)$} & 20.2 & 22.7 & - \\
\hline
\end{tabular}

\subsection{Crack propagation analysis method}

The remaining fatigue life of the cracked welded connection can be estimated through crack propagation analysis based on a crack growth relationship proposed by Paris and Erdogan [24], known as the Paris law given in Eq. (27):

$\frac{\mathrm{d} a}{\mathrm{dN}}= \begin{cases}C(\Delta \mathrm{K})^{m} & \left(\Delta \mathrm{K} \geq \Delta K_{\mathrm{th}}\right) \\ 0 & \left(\Delta \mathrm{K}<\Delta K_{\mathrm{th}}\right)\end{cases}$

where, $a$ is the crack size; $N$ is the number of stress cycles; $C$ and $m$ are the material dependant crack growth parameters; $\Delta K_{\mathrm{th}}$ is the threshold stress intensity factor range; and $\Delta K$ is the stress intensity factor range, which can be calculated by Eq. (28):

$\Delta \mathrm{K}=K_{\max }-K_{\min }=Y \Delta \sigma \sqrt{\pi \mathrm{a}}$

where, $K_{\max }$ and $K_{\min }$ are the maximum and minimum stress intensity factors corresponding to the maximum and minimum applied nominal stresses; $\Delta \sigma$ is the applied nominal stress range.

Integrating Eq. (27) from the initial crack size $a_{0}$ to the critical crack size $a_{\mathrm{cr}}$ and then substituting $\Delta K$ by Eq. (28), the fatigue crack propagation life in terms of the number of stress cycles can be obtained as:

$N=\int_{a_{0}}^{a_{\mathrm{cr}}} \frac{\mathrm{d} a}{C(\Delta \mathrm{K})^{m}}=\int_{a_{0}}^{a_{\mathrm{cr}}} \frac{\mathrm{d} a}{C(Y \Delta \sigma \sqrt{\pi \mathrm{a}})^{m}}$

where, $a_{0}$ and $a_{\mathrm{cr}}$ are the initial and critical crack size, respectively.

In this study, the crack propagation analysis of the critical welded connection was performed in accordance with a flowchart as shown in Fig. 13. It includes two major stages, the equivalent stress range $\Delta \sigma_{\text {eq }}$ calculation and the crack growth simulation under constant amplitude stress range $\Delta \sigma_{\text {eq. }}$. The variable amplitude stress history generated by a single train passage was treated as a typical stress block and the equivalent stress range $\Delta \sigma_{\text {eq }}$ was calculated based on the assumption of that, an equivalent crack extension was produced by a single stress cycle of $\Delta \sigma_{\text {eq }}$ and by several stress cycles due to one train passage. Subsequently, the crack propagation life of each critical welded connection, in terms of the number of train passages, was calculated under the constant amplitude stress range $\Delta \sigma_{\text {eq }}$.

As shown in Fig. 13, the detailed procedure to calculate the equivalent stress range $\Delta \sigma_{\text {eq }}$ was as follows:

(1) The nominal stress history of the critical welded connection generated by a single train passage was converted into a stress spectrum (stress range $\Delta \sigma_{i}$ versus number of stress cycles $n_{i}$ ) by the Rainflow cycle counting method [22].

(2) The low stress cycles, in which the SIF range $\Delta K_{i}$ was below the threshold SIF range $\Delta K_{\mathrm{th}}$, were cut off and an updated stress spectrum $\left(\Delta \sigma_{j}\right.$ versus $\left.n_{j}\right)$ was obtained.

(3) A small crack extension $\Delta a_{j}$ within each stress cycle $\Delta \sigma_{j}$ was calculated cycle by cycle based on the Paris law and the total crack extension $\Delta a$ and the updated crack size $a_{N}$ were obtained.

(4) Based on the equivalent crack extension assumption, the equivalent stress range $\Delta \sigma_{\text {eq }}$ was calculated:
$\Delta \sigma_{\mathrm{eq}}=\left[\Delta \mathrm{a} / C(Y \sqrt{\pi \bar{a}})^{m}\right]^{1 / m}$

where, $\Delta a$ is the total crack extension size during one train passage; $\bar{a}$ is the average crack size estimated as $\bar{a}=\left(a_{0}+a_{N}\right) / 2$.

The variable nominal stress histories applied on the critical welded 653 connections CH-A05\&06, BW-05\&06, ST-A05 and FW-15W8 due to 654 one passage of the high-speed train ETR500Y were used to calculate 655 the corresponding equivalent stress range $\Delta \sigma_{\text {eq. }}$. In each critical connec- 656 tion, the SIF range $\Delta K_{i}$ induced by any stress cycle of the loading history 657 was below the threshold $\Delta K_{\mathrm{th}}=63 \mathrm{MPa} \cdot \mathrm{mm}^{1 / 2}$, and no crack extension 658 took place in any critical welded connection. Therefore, the estimated 659 equivalent stress range $\Delta \sigma_{\text {eq }}$ was equal to zero. However, in this 660 study, the threshold $\Delta K_{\text {th }}$ was not taken into account in calculations of 661 the equivalent stress ranges, so as to evaluate the relative fatigue crack 662 propagation life of the concerned welded connections.

663

Referring to Fig. 13, the fatigue crack growth calculation under the 664 constant amplitude stress cycles (i.e. under the equivalent stress range 665 $\left.\Delta \sigma_{\text {eq }}\right)$ was carried out as the following steps:

666

(1) A small crack extension size $\Delta a_{i}=0.001 a_{i-1}$ was adopted and the 667 current crack size $a_{i}=a_{i-1}+\Delta a_{i}$ was calculated.

668

(2) The SIF ranges $\Delta K_{i-1}$ and $\Delta K_{i}$ associated with the crack size $a_{i-1} 669$ and $a_{i}$ were calculated under the equivalent stress range $\Delta \sigma_{\text {eq }} \quad 670$

(3) If the difference between $\Delta K_{i}$ and $\Delta K_{i-1}$ was less than $0.001 \Delta K_{i}, 671$ i.e. $\left(\Delta K_{i}-\Delta K_{i-1}\right)<0.001 \Delta K_{i}$, computation was continued; other- 672 wise, the crack extension should be modified as $\Delta a_{i}=\Delta a_{i} / 2$ and 673 computation was returned back to step (2).

(4) The average crack growth rate was estimated by Eq. (31), and the 675 number of cycles $\Delta N_{i}$ that needed to propagate the crack exten- 676 sion $\Delta a_{i}$ was calculated by Eq. (32). The total number of cycles 677 $N_{i}$ corresponding to the crack size $a_{i}$ was obtained as $N_{i}=678$ $N_{i}+\Delta N_{i}$ at the current step $i$.

$\overline{(\mathrm{d} a / \mathrm{d} N)_{i}}=C\left(\overline{\Delta K_{i}}\right)^{m}$

where, $\overline{\Delta K_{i}}$ is the mean value of $\Delta K_{i}$ and $\Delta K_{i-1}$.

$\Delta N_{i}=\Delta a_{i} / \overline{(\mathrm{d} a / \mathrm{d} N)_{i}}$

(5) Steps (1) to (4) were repeated until the crack size $a_{i}$ exceeded the 683 critical size $a_{\mathrm{cr}}$. Finally, the crack size versus the number of cycles 684 curve $a_{i}-N_{i}$ could be obtained.

\section{Results and discussion}

According to the flowchart given in Fig. 13, the algorithms for equiva- 688 lent stress range calculation and crack propagation analysis were pro- 689 grammed in MATLAB [37]. The equivalent stress range $\Delta \sigma_{\text {eq }}$ of each 690 critical connection was calculated based on the variable nominal stress 691 history induced by a single train passage and the results are shown in 692 


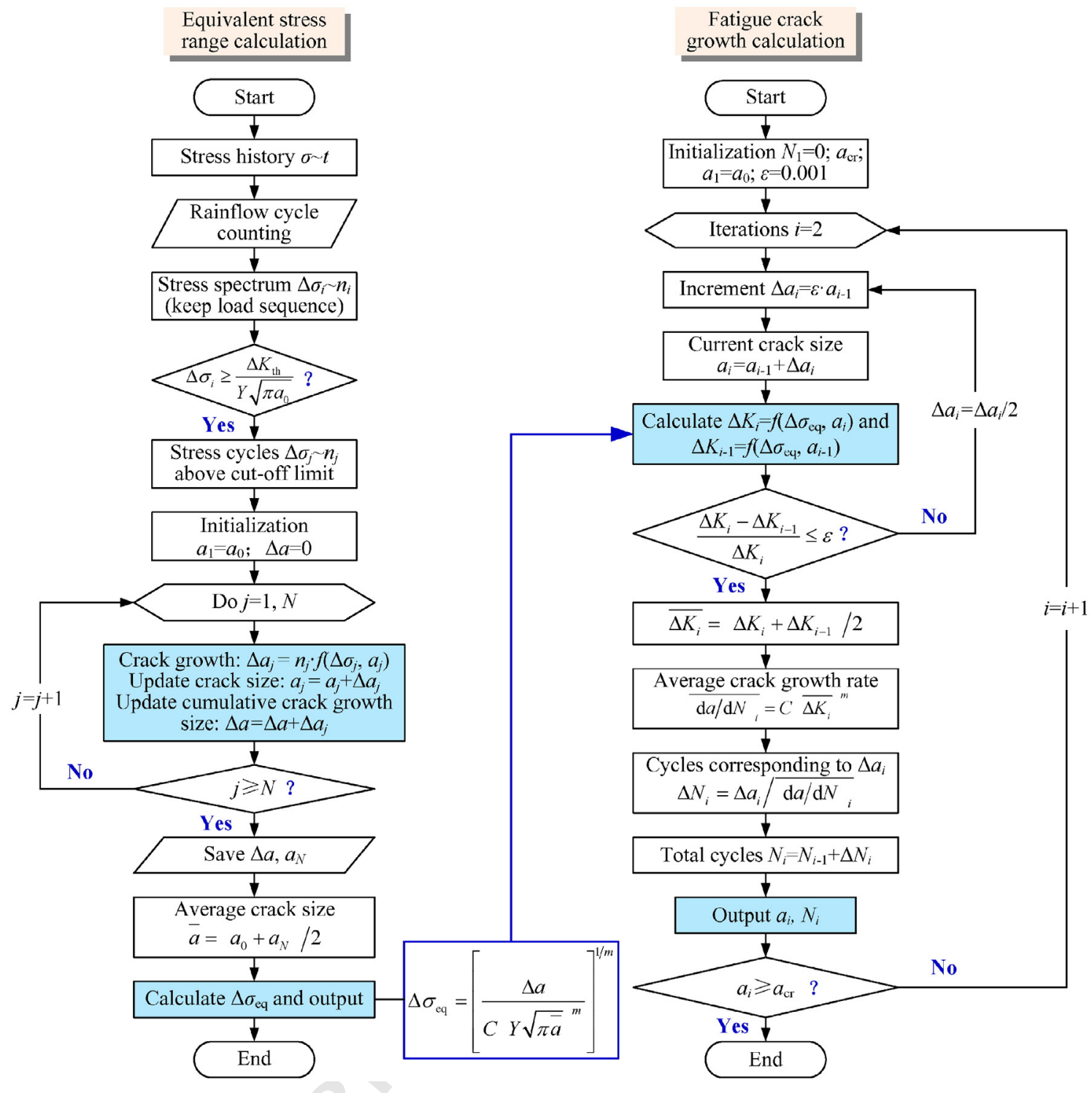

Fig. 13. Flowchart of fatigue crack propagation analysis.

Table 3. Then, the fatigue crack propagation under the constant stress range $\Delta \sigma_{\text {eq }}$ was carried out and the crack growth curves (i.e. crack size $a$ versus number of train passages $N_{\text {tr }}$ ) with different initial crack sizes $a_{0}$ are shown in Fig. 14. With the crack growth curve, the fatigue life during which the crack propagated from the initial size $a_{0}$ to the critical size $a_{\mathrm{cr}}$ was obtained for each critical welded connection as listed in Table 3.

As shown in Fig. 14, the fatigue crack propagation life decreases as the initial crack size increases. Taking connection ST-A05 shown in Fig. $14 \mathrm{c}$ as an example, the fatigue propagation life represented by $N_{\text {tr }}$ reduces approximately $20 \%$ when the initial crack size increases from $0.10 \mathrm{~mm}$ to $0.25 \mathrm{~mm}$. It is found in Fig. 14 that the crack propagates slowly at the early stage which forms the major part of the propagation 704 life, while it grows faster at the later period. It also indicates that the 705 final critical crack size has less effect on the fatigue propagation life as 706 compared to the initial crack size. Actually, it is more appropriate to 707 choose the crack size when it is accelerating as the allowable critical 708 size, so that enough time is available for repair, retrofitting or replace- 709 ment. For connections BW-05\&06 and ST-A05 as shown in Fig. 14b 710 and c, fatigue crack repair and reinforcement are recommended when 711 the crack size grows to $5 \mathrm{~mm}$ although the critical size estimated by 712 the LEFM $K$ criterion is about $20 \mathrm{~mm}$.

Table 3

Fatigue crack propagation analysis results of the critical welded connections.

\begin{tabular}{|c|c|c|c|c|c|c|}
\hline \multirow{2}{*}{ Critical connection } & \multirow{2}{*}{$\begin{array}{l}\Delta \sigma_{\mathrm{eq}} \\
{[\mathrm{MPa}]}\end{array}$} & \multirow{2}{*}{$\begin{array}{l}a_{\mathrm{cr}} \\
{[\mathrm{mm}]}\end{array}$} & \multicolumn{4}{|c|}{ Number of train passages $N_{\mathrm{tr}}$ when crack propagates from $a_{0}$ to $a_{\mathrm{cr}}$} \\
\hline & & & $a_{0}=0.10 \mathrm{~mm}$ & $a_{0}=0.15 \mathrm{~mm}$ & $a_{0}=0.20 \mathrm{~mm}$ & $a_{0}=0.25 \mathrm{~mm}$ \\
\hline $\mathrm{CH}-\mathrm{A} 05 \& 06$ & 7.79 & 11.6 & $5.218 \mathrm{E} 08$ & 4.874E08 & 4.618E08 & $4.415 \mathrm{E} 08$ \\
\hline BW-05\&06 & 8.40 & 19.5 & $2.035 \mathrm{E} 10$ & $1.891 \mathrm{E} 10$ & $1.779 \mathrm{E} 10$ & $1.685 \mathrm{E} 10$ \\
\hline ST-A05 & 7.28 & 20.2 & $1.765 \mathrm{E} 10$ & $1.606 \mathrm{E} 10$ & $1.493 \mathrm{E} 10$ & $1.405 \mathrm{E} 10$ \\
\hline${ }^{\mathrm{a}} \mathrm{FW}-15 \mathrm{~W} 8$ & 3.69 & 20.2 & 4.093E09 & 4.007E09 & 3.923E09 & $3.841 \mathrm{E} 09$ \\
\hline
\end{tabular}

a The initial half crack size of the connection FW-15W8 is $\left(15+a_{0}\right) \mathrm{mm}$. 

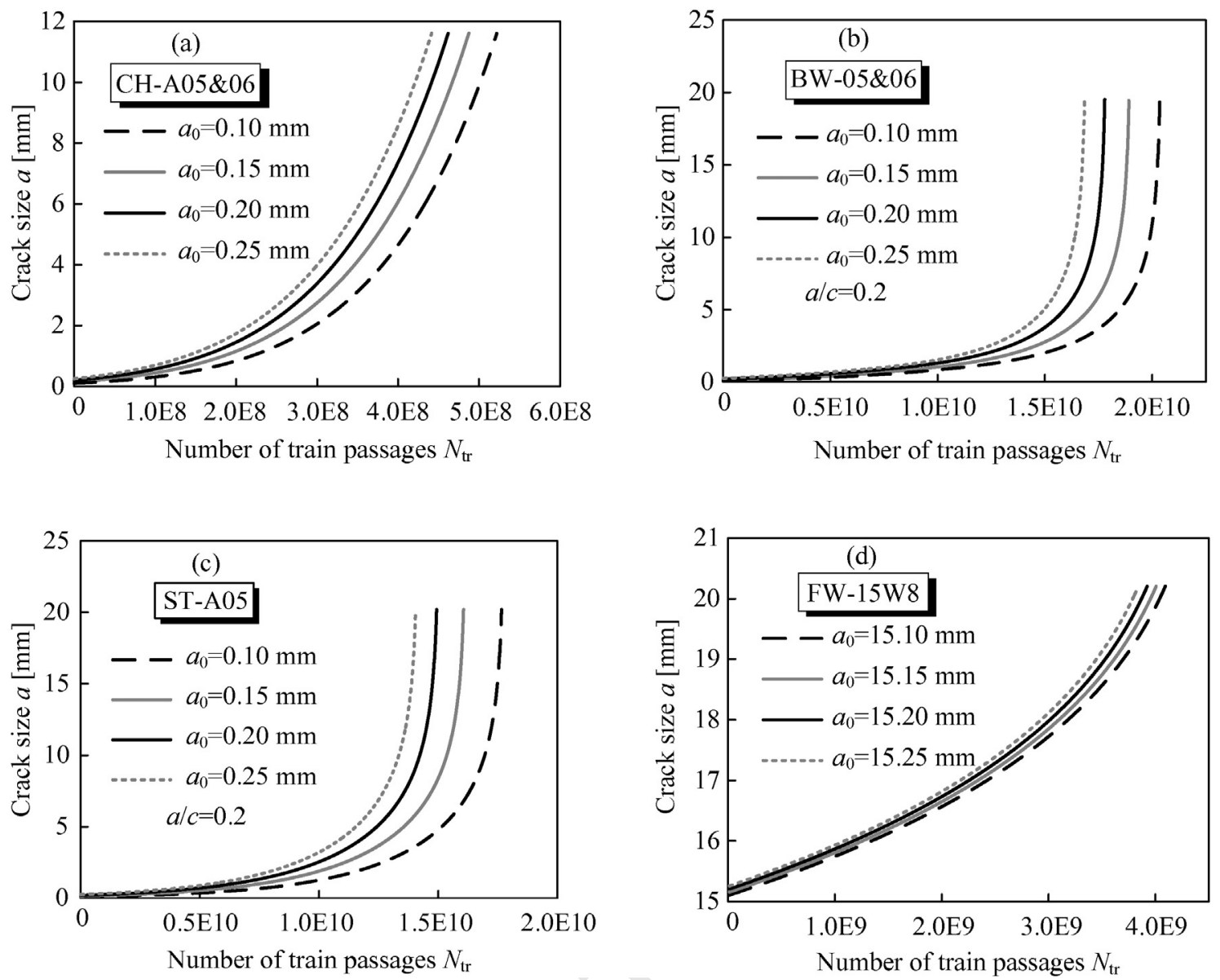

Fig. 14. Fatigue crack growth curves of the critical welded connections: (a) connection CH-A05\&06; (b) connection BW-05\&06; (c) connection ST-A05 and (d) connection FW-15W8.

The fatigue propagation life of the studied critical welded connections with varying initial crack sizes is clearly shown in Fig. 15. The cope hole detail $\mathrm{CH}-\mathrm{A} 05 \& 06$ and the load carrying fillet weld connection FW-15W8 have a relatively shorter fatigue propagation life compared with the assembling butt weld connection BW-05\&06 and the transverse stiffener fillet welded detail ST-A05.

As shown in Fig. 16, the fatigue life of the four critical welded connections predicted by the LEFM approach in the present study is compared with that estimated by the traditional $S-N$ method (according to Eurocode 3 [2]) performed in the previous research of the authors [1]. In the previous study, fatigue damage $D$ due to one passage of the high-speed train was presented and fatigue life is calculated as the reciprocal of $D$ on the basis of Palmgren-Miner linear damage rule. In general, fatigue life of each critical welded connection estimated by the traditional $S-N$ method is relatively larger than that predicted by the

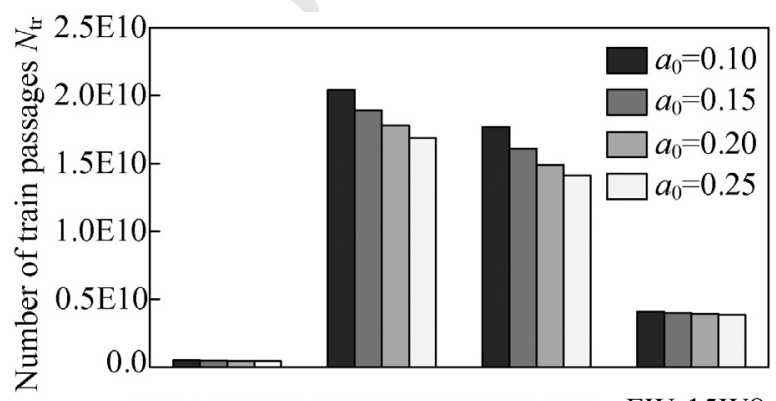

CH-A05\&06 BW-05\&06 ST-A05 FW-15W8

Fig. 15. Fatigue crack propagation life of the critical welded connection with varying initial crack sizes.
LEFM approach, which seems reasonable as the $S-N$ method takes ac- 729 count of the total fatigue life including crack initiation and propagation. 730 However, a similar tendency is predicted by both methods that the fa- 731 tigue life of connections CH-A05\&06 and FW-15W8 is relatively shorter 732 than that of connections BW-05\&06 and ST-A05.

\section{Conclusions}

In this study, an enhanced fatigue evaluation for a steel-concrete 735 composite railway bridge, the Sesia viaduct, was carried out after a pre- 736 liminary fatigue assessment based on the traditional $\mathrm{S}-\mathrm{N}$ method in the 737 previous work [1]. Fatigue crack propagation analyses based on the 738 Paris law and LEFM were performed on the critical welded connections, 739 which were identified by the preliminary fatigue assessment. The fol- 740 lowing conclusions can be drawn from the present study:

741

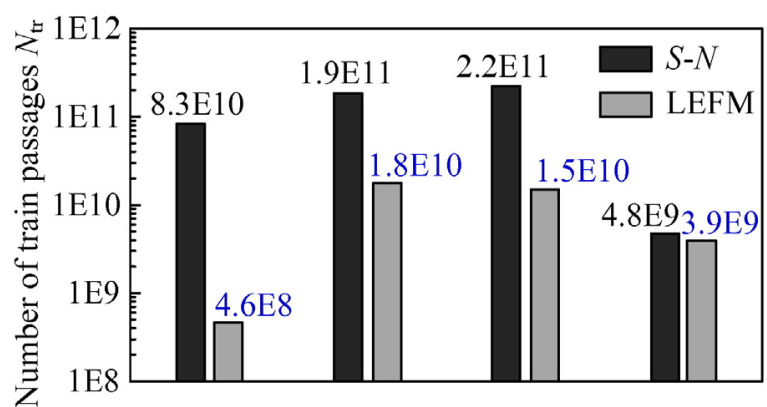

CH-A05\&06 BW-05\&06 ST-A05 FW-15W8

Fig. 16. Fatigue life evaluated by the traditional $S-N$ method and the LEFM approach. 
(1) Initial cracks were introduced into the identified critical welded connections CH-A05\&06, BW-05\&06, ST-A05 and FW-15W8, and the refined local FE models with assumed cracks were incorporated into the global FE model of the bridge span. The applicability and the accuracy of the empirical SIF formulas for the critical welded connections were validated by dynamic analyses using the global-local FE model with three-dimensional cracks.

(2) The variable amplitude stress history sustained by each cracked connection due to one passage of the high-speed train ETR500Y was converted into one stress cycle with an equivalent stress range $\Delta \sigma_{\text {eq, }}$, based on the proposed equivalent crack extension assumption. The fatigue crack propagation under constant amplitude stress range $\Delta \sigma_{\text {eq }}$ was analyzed based on the Paris law and LEFM. The crack growth curve of each critical connection, expressed by crack size versus number of train passages, was obtained and the fatigue propagation life was predicted. The initial crack size has a significant effect on the fatigue propagation life, while the final critical crack size is less important.

(3) In fatigue assessment of the four concerned critical welded connections, fatigue life predicted by the LEFM approach in the present study is shorter than that evaluated by the $S-N$ method in the previous research [1]. Fatigue life of connections $\mathrm{CH}-\mathrm{A} 05 \& 06$ and FW-15W8 is relatively shorter than that of the connections BW$05 \& 06$ and ST-A05, as estimated by both methods. The LEFM provides an alternative and a more general approach to evaluate the fatigue life of welded details, especially when the traditional $S-N$ method is inapplicable.

\section{Acknowledgments}

This work was sponsored by the National Natural Science Foundation of China (Grant Nos. 51408013 and 51478244) and the Natural Science Foundation of Beijing (Grant No. 8154040). The financial support from the China Postdoctoral Science Foundation (Grant Nos. 2014M560035 and 2015T80031) was also greatly appreciated.

\section{References}

[1] H. Zhou, K. Liu, G. Shi, Y.Q. Wang, Y.J. Shi, G. De Roeck, Fatigue assessment of a composite railway bridge for high speed trains. Part I: modeling and fatigue critical details, J. Constr. Steel Res. 82 (2013) 234-245.

[2] EN 1993-1-9 Eurocode 3, Design of Steel Structures - Part 1-9: Fatigue, European Committee for Standardization (CEN), Brussels, 2005.

[3] BS 5400, Steel, Concrete And Composite Bridges - Part 10: Code of Practice for Fatigue, British Standards Institute (BSI), London, 1980.

[4] American Association of State Highway Transportation Officials (AASHTO), LRFD Bridge Design Specifications, third ed. AASHTO, Washington, DC, 2004

[5] A.G. Palmgren, Die Lebensdauer von Kugellagern (life length of roller bearings), VDI Z. 68 (14) (1924) 339-341.

[6] M.A. Miner, Cumulative damage in fatigue, J. Appl. Mech. Trans. ASME 12 (3) (1945) A159-A164.

[7] J.M. Barsom, S.T. Rolfe, Fracture and Fatigue Control in Structures: Applications of Fracture Mechanics, third ed. West Conshohocken, PA, ASTM, 1999.

[8] T.L. Anderson, Fracture Mechanics: Fundamentals and Applications, third ed. CRC Press, Boca Raton, FL, 2004.

[9] T.D. Righiniotis, M.K. Chryssanthopoulos, Probabilistic fatigue analysis under constant amplitude loading, J. Constr. Steel Res. 59 (7) (2003) 867-886.
[10] T.D. Righiniotis, M.K. Chryssanthopoulos, Fatigue and fracture simulation of welded 796 bridge details through a bi-linear crack growth law, Struct. Saf. 26 (2) (2004) 797 141-158.

[11] C.S. Wang, A.R. Chen, W.Z. Chen, Y. Xu, Application of probabilistic fracture mechan- 799 ics in evaluation of existing riveted bridges, Bridge Struct. Assess. Des. Constr. 2 (4) 800 (2006) 223-232.

[12] Y. Wang, Z.X. Li, A.Q. Li, Fatigue crack growth model for assessing reliability of box- 802 girders for cable-stayed bridge combining SHMS with strain data, Theor. Appl. Fract. 803 Mech. 55 (1) (2011) 60-67.

[13] M. Aygül, M. Al-Emrani, Z. Barsoum, J. Leander, Investigation of distortion-induced 805 fatigue cracked welded details using 3D crack propagation analysis, Int. J. Fatigue 806 64 (2014) 54-66.

[14] M. Aygül, M. Al-Emrani, Z. Barsoum, J. Leander, An investigation of distortion- 808 induced fatigue cracking under variable amplitude loading using 3D crack propaga- 809 tion analysis, Eng. Fail. Anal. 45 (2014) 151-163.

[15] K. Liu, E. Reynders, G. De Roeck, G. Lombaert, Experimental and numerical analysis 811 of a composite bridge for high-speed trains, J. Sound Vib. 320 (1-2) (2009) 812 201-220.

[16] G. Chellini, L. Nardini, W. Salvatore, Dynamic identification and modelling of steel- 814 concrete composite high-speed railway bridges, Struct. Infrastruct. Eng. 7 (11) 815 (2011) 823-841.

[17] G. Chellini, F.V. Lippi, W. Salvatore, A multidisciplinary approach for fatigue assess- 817 ment of a steel-concrete high-speed railway bridge on Sesia river, Struct. Infrastruct. 818 Eng. 10 (2) (2014) 189-212.

[18] B. Peeters, G. De Roeck, Reference-based stochastic subspace identification for 820 output-only modal analysis, Mech. Syst. Signal Process. 13 (6) (1999) 855-878. 821

[19] K. Liu, G. Lombaert, G. De Roeck, Dynamic analysis of multispan viaducts with weak 822 coupling between adjacent spans, J. Bridg. Eng. 19 (1) (2014) 83-90. 823

[20] ABAOUS, Standard User's Manual Version 6.4, Hibbitt, Karlsson \& Sorensen Inc., 824 Providence, RI, 2004.

[21] R.W. Clough, J. Penzien, Dynamics of Structures, McGraw-Hill, New York, 1993.

[22] S.D. Downing, D.F. Socie, Simple rainflow counting algorithms, Int. J. Fatigue 4 (1) 827 (1982) 31-40.

[23] J. Schijve, Fatigue of Structures and Materials, Springer, Netherlands, 2009.

[24] P. Paris, F. Erdogan, A critical analysis of crack propagation laws, J. Basic Eng. 85 (4) 830 (1963) 528-534

[25] J.C. Newman, I.S. Raju, An empirical stress-intensity factor equation for the surface 832 crack, Eng. Fract. Mech. 15 (1-2) (1981) 185-192.

[26] J.C. Newman, I.S. Raju, Stress intensity factor equation for cracks in three- 834 dimensional finite bodies subjected to tension and bending loads, NASA Technical 835 Memorandum 85793, National Aeronautics and Space Administration, Langley Re- 836 search Center, Virginia, 1984.

[27] BS 7910, Guide to Methods for Assessing the Acceptability of Flaws in Metallic Struc- 838 tures, British Standards Institution (BSI), London, 2005.

[28] A. Hobbacher, Stress intensity factors of welded joints, Eng. Fract. Mech. 46 (2) 840 (1993) 173-182. 841

[29] H. Tada, P.C. Paris, G.R. Irwin, The Stress Analysis of Cracks Handbook, ASME, New 842 York, 2000.

[30] J.E. Noblett, R.M. Andrews, A stress intensity factor solution for root defects in fillet 844 and partial penetration welds, TWI Research Report 575/1996, TWI, Cambridge, 845 1996.

[31] BS 7608, Code of Practice for Fatigue Design and Assessment of Steel Structures, 847 British Standards Institution (BSI), London, 1993.

[32] EN 10025, Hot Rolled Products of Structural Steels, European Committee for Stan- 849 dardization (CEN), Brussels, 2004.

[33] A.M.P. De Jesus, R. Matos, B.F.C. Fontoura, C. Rebelo, L.S. Da Silva, M. Veljkovic, A 851 comparison of the fatigue behavior between S355 and S690 steel grades, J. Constr. 852 Steel Res. 79 (2012) 140-150.

[34] A.F. Hobbacher, The new IIW recommendations for fatigue assessment of welded 854 joints and components - a comprehensive code recently updated, Int. J. Fatigue 855 31 (1) (2009) 50-58.

[35] M.H. El Haddad, T.H. Topper, K.N. Smith, Prediction of non propagating cracks, Eng. 857 Fract. Mech. 11 (3) (1979) 573-584. 858

[36] M. Lukić, C. Cremona, Probabilistic assessment of welded joints versus fatigue and 859 fracture, J. Struct. Eng. 127 (2) (2001) 211-218.

[37] MATLAB, MATLAB: The Language of Technical Computing. Version, The MathWorks 861 Inc., Natick, MA, 2008. 